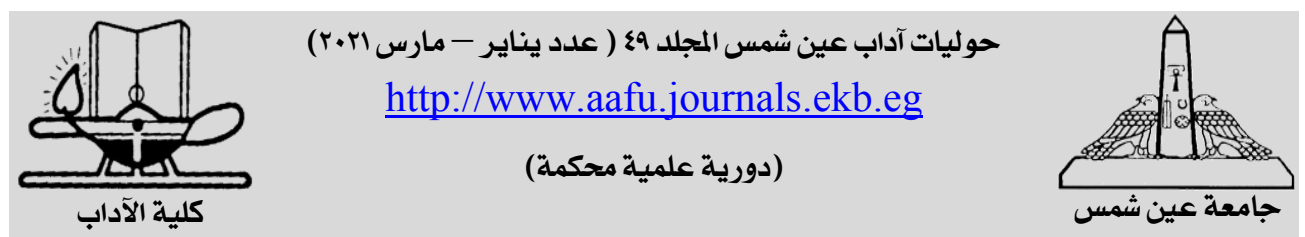

\title{
العقوبات السياسية لوزراء المشرق الإسلامي في القرنين الرابع والخامس الهبراء الهريين
}

\author{
*فراء عازم عليان الشراري \\ كلية الثريعة والقانون ـ قسم الدراسات ـ جامعة الجوف ـ السعودية \\ Dr_gamalshakra@yahoo.com
}

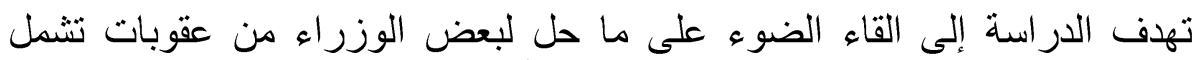

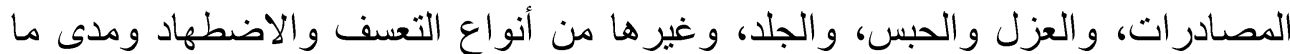

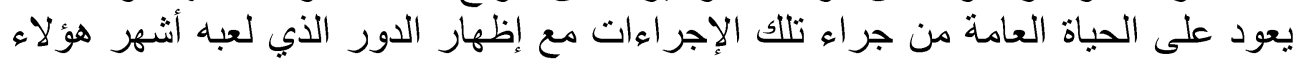

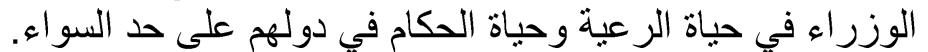

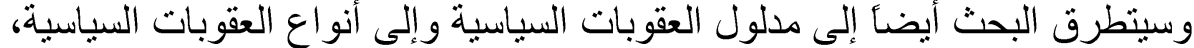

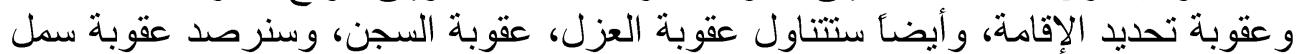

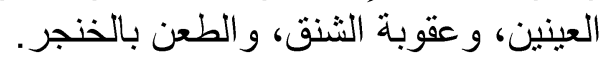
و أخير أ نعرض بـ في الخاتمة لأهم ما توصلنا إليه من نتائج.

الكلمات المفتاحية: المصادرات، العزل والحبس، التبه التعسف والاضطهاد، مدلول العقوبات السباسية. 


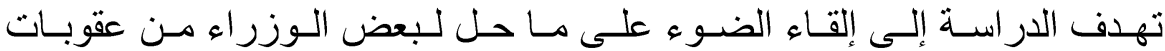

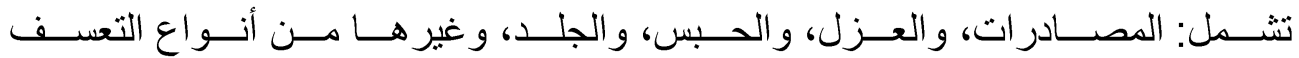

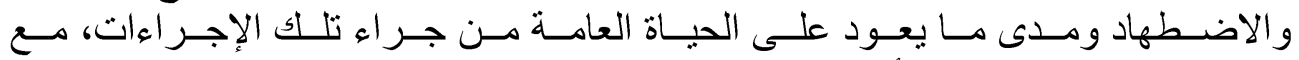

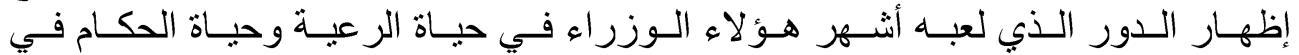
دولهز على حد سواء.

\section{تمهيخ}

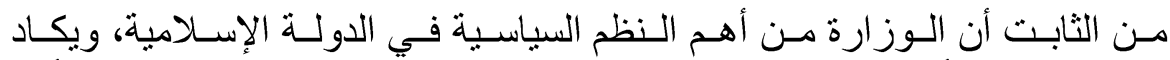

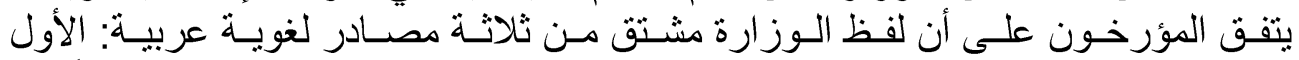

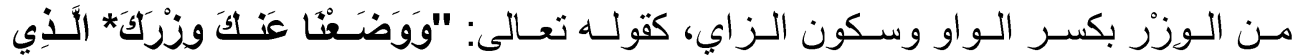

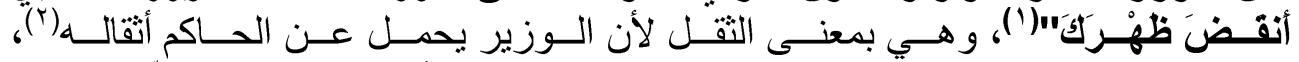

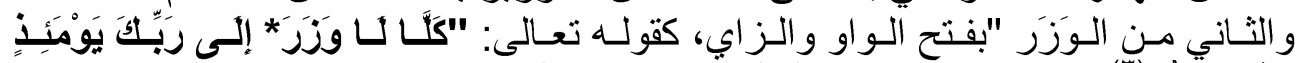

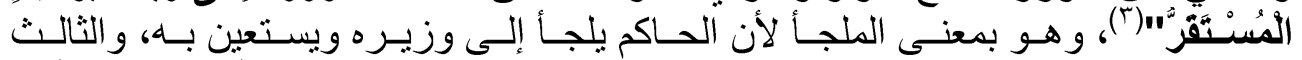

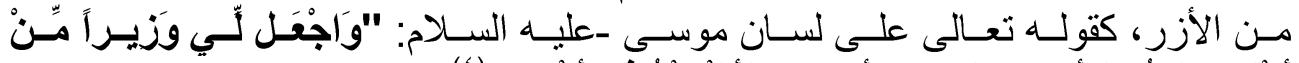

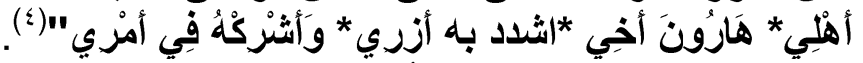

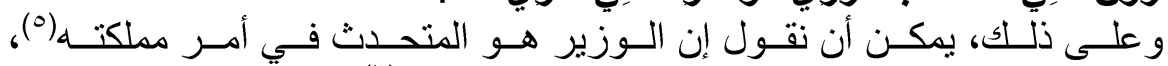

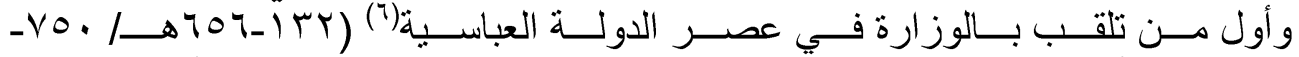

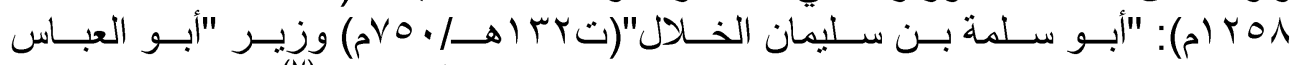

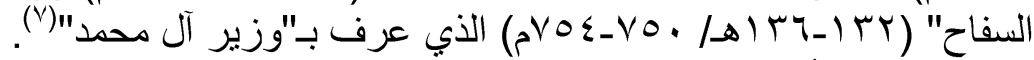

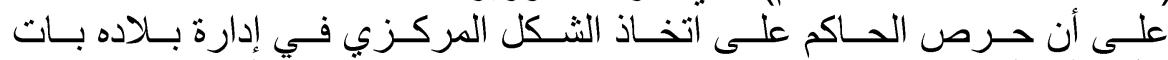

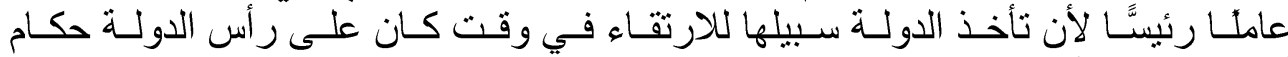

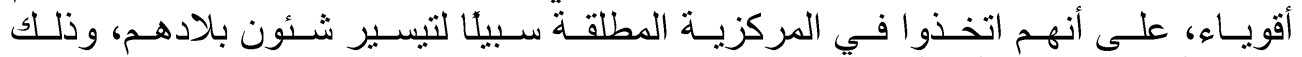

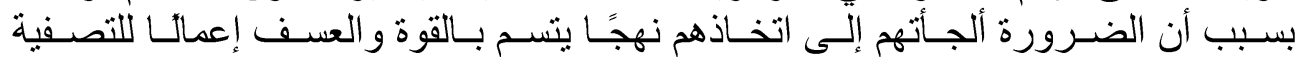

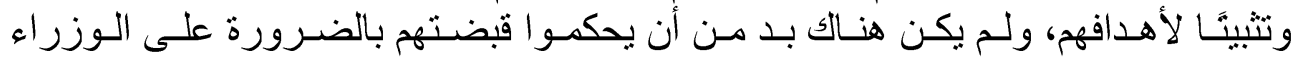
الذين صارو أداة لتدبير شئون السياسة.

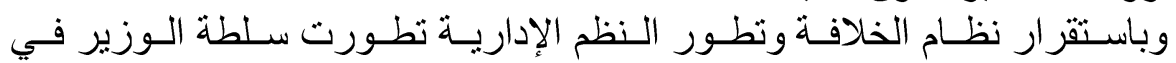

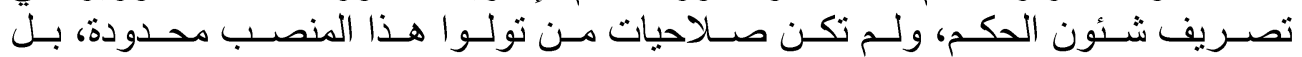

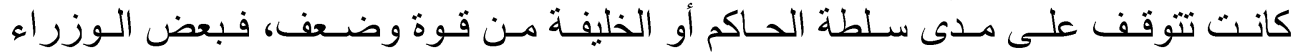

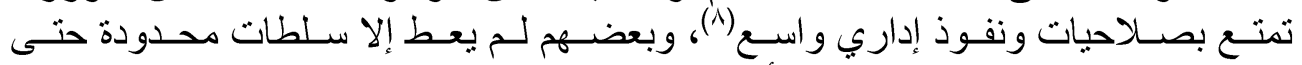

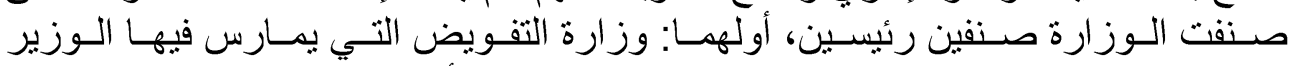

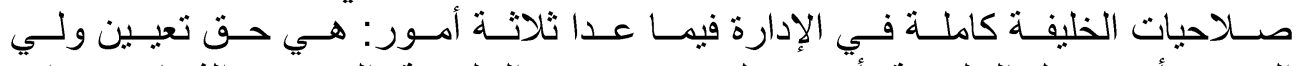

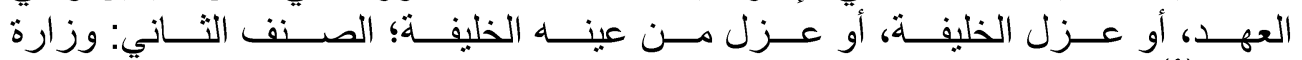

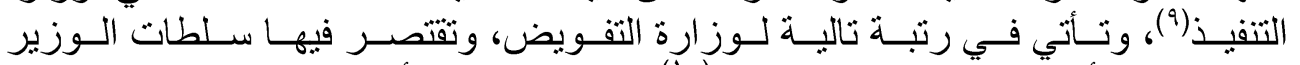

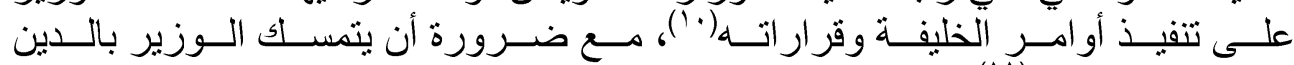
و العدل في الحالتين(

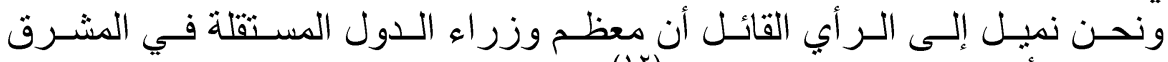

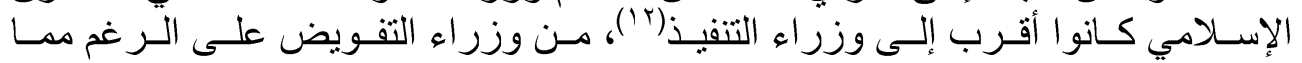
قدموه من الخبرة، والكفاءة، والمقدرة على إدارة شئون البلاءد.

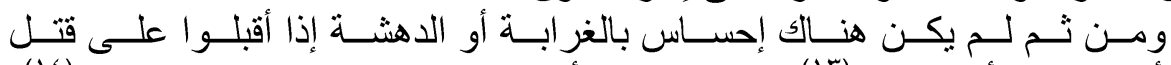

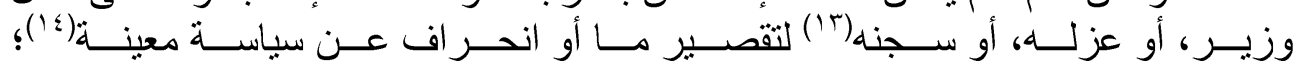




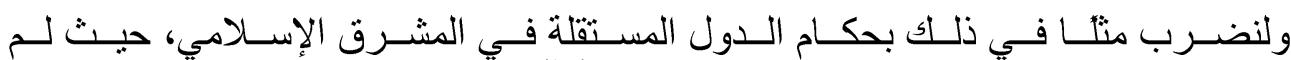

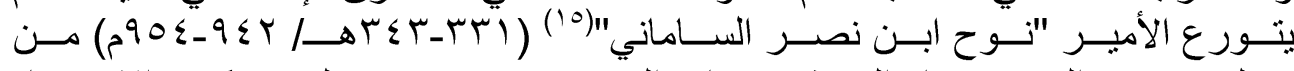

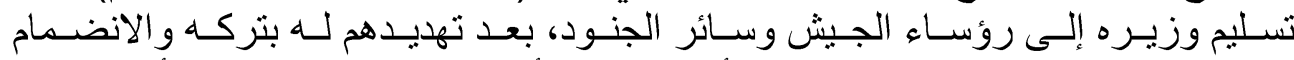

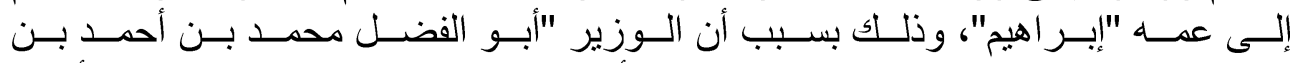

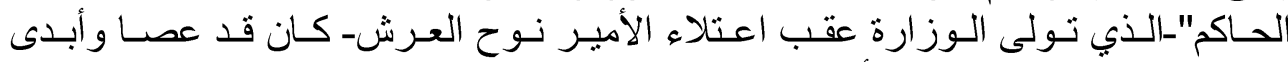

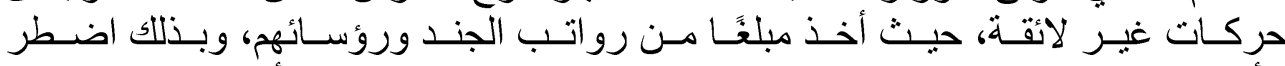

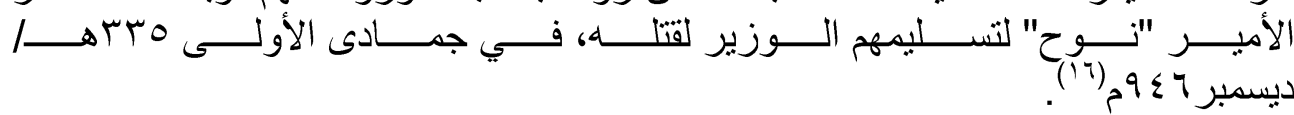

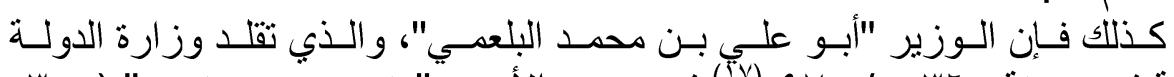

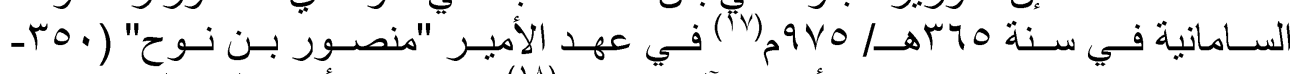

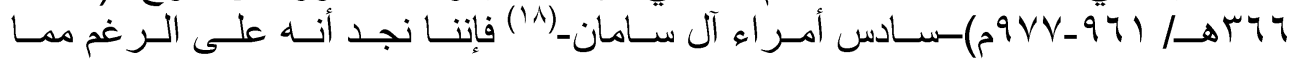

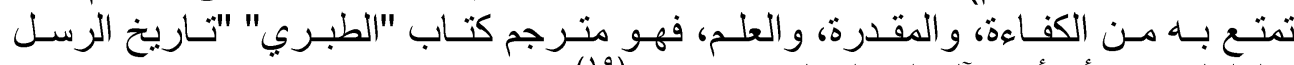

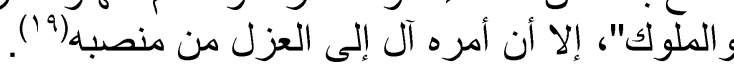

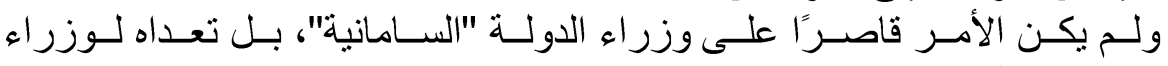

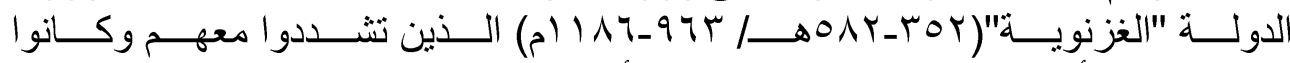

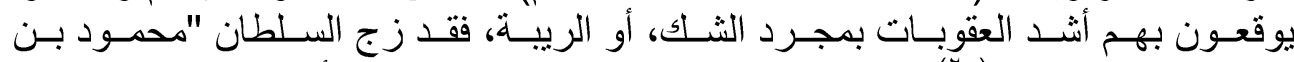

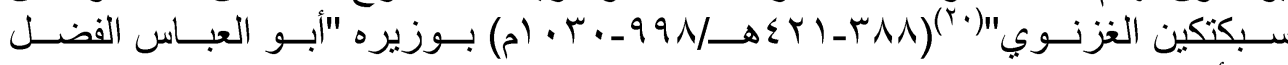

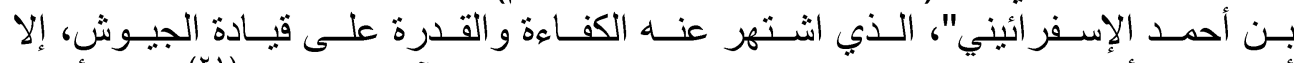

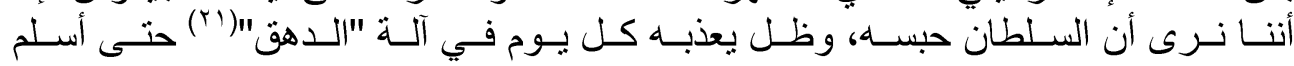

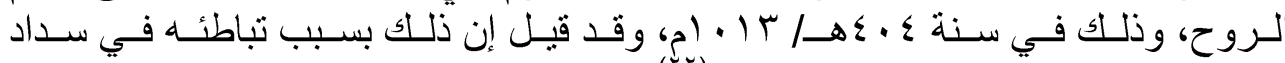

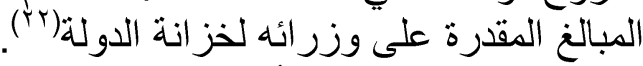

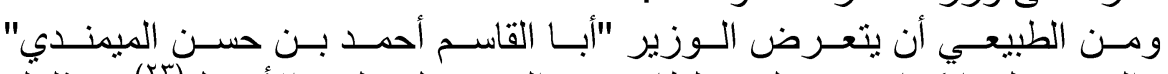

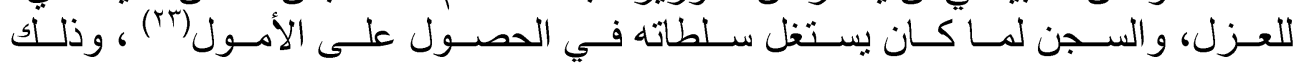

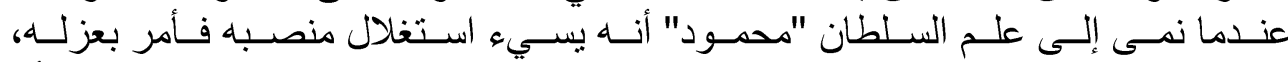

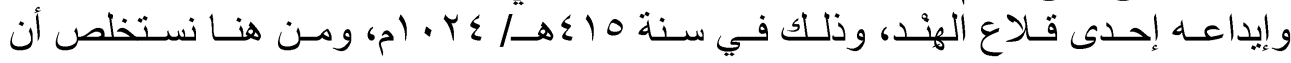

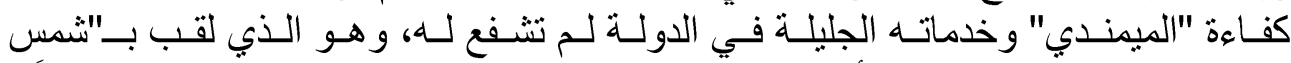

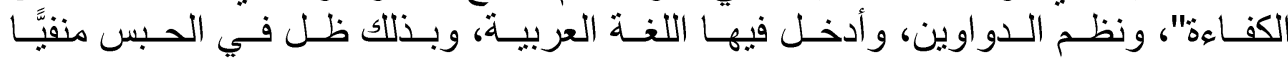

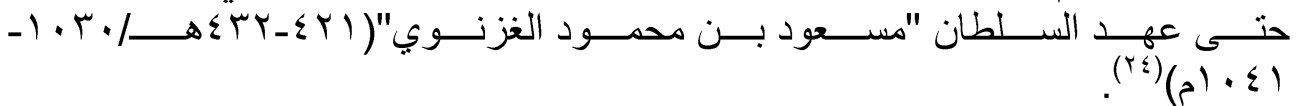

\section{العقوبات السياسية لوزراء المشرق الإسلامي

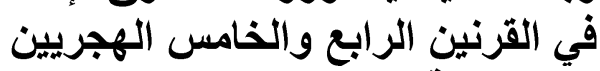

\section{1 - مدلول العقوبات السياسية:}

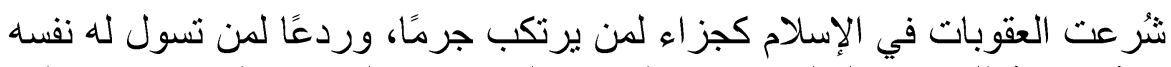

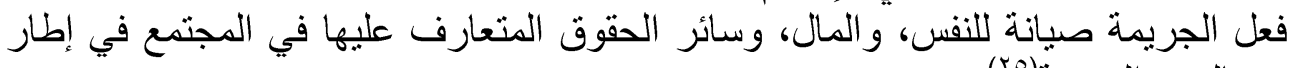
مصالحهم الدنيوية (ro)

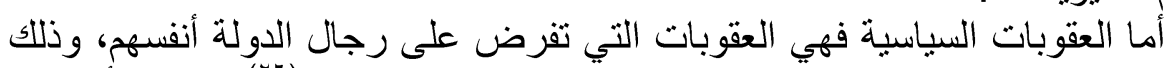

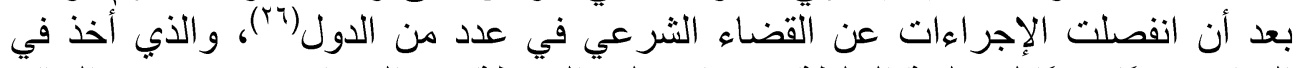

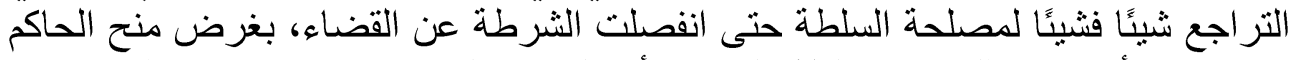

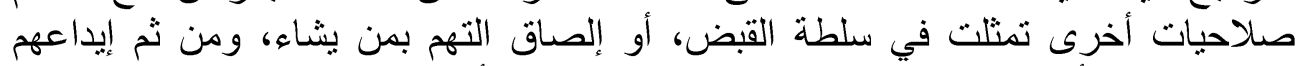

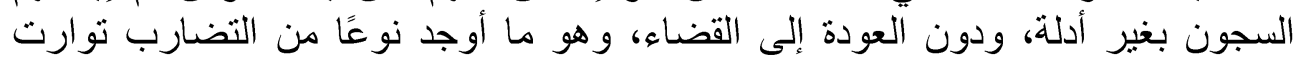




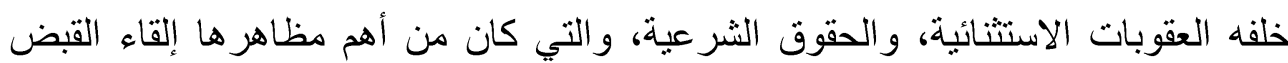

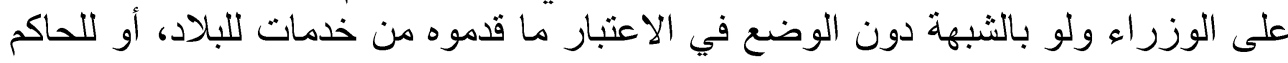

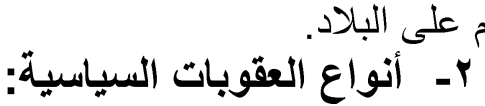 عقوية تحديد الإقامة:}

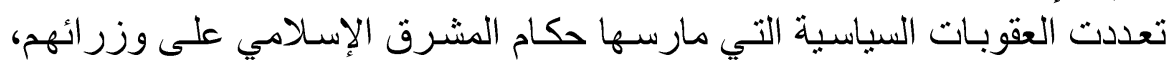

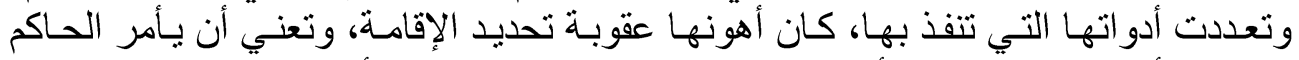

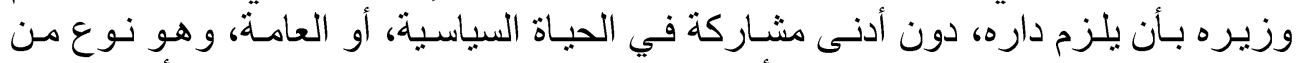

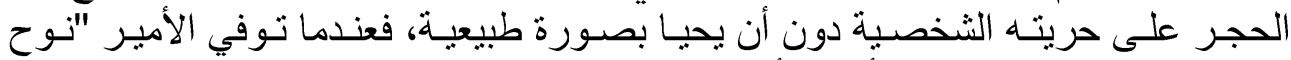

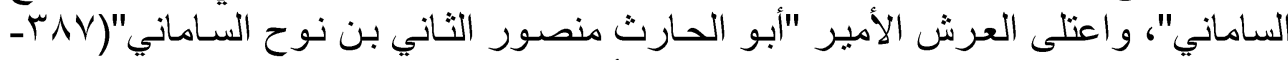

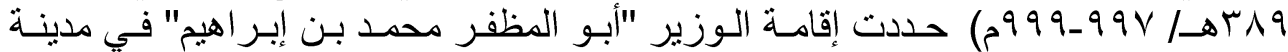

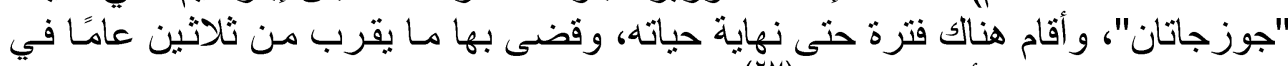

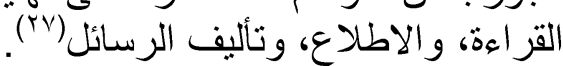

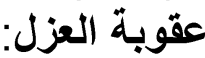

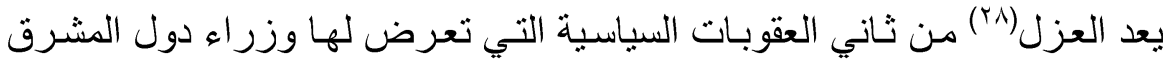

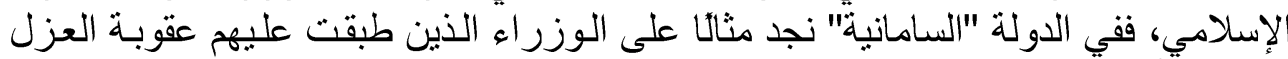

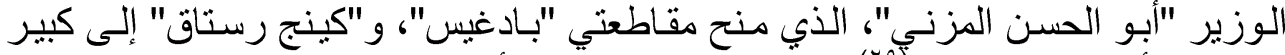

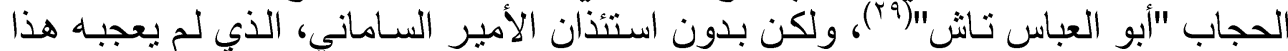

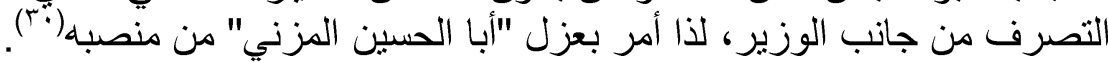

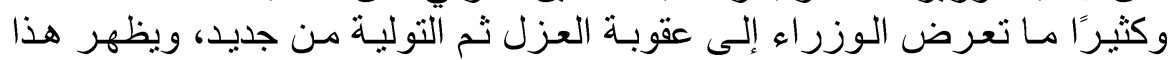

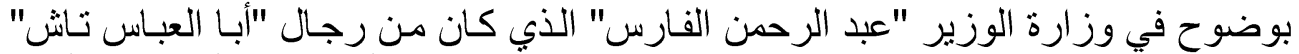

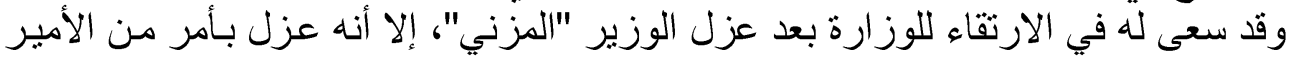

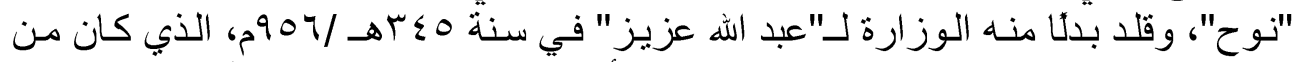

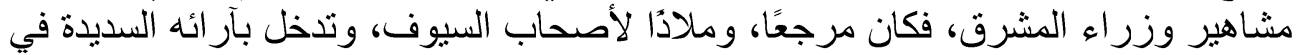

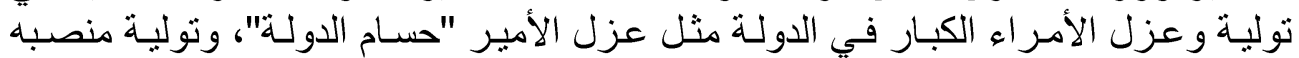

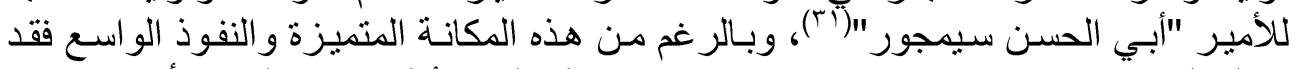

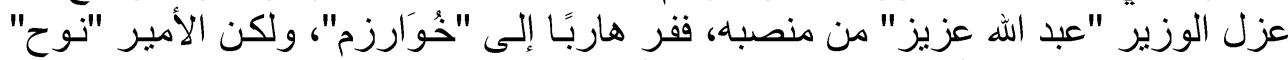

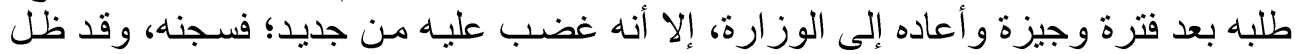

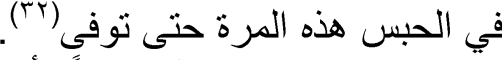

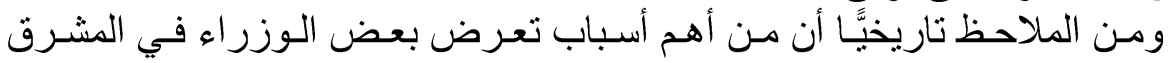

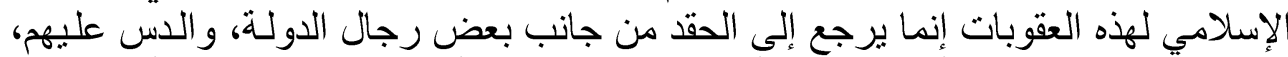

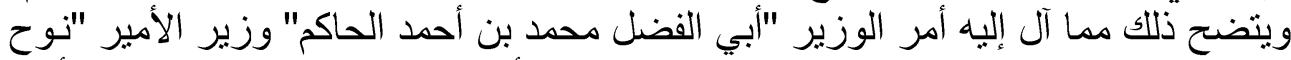

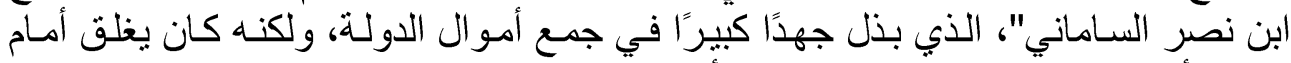

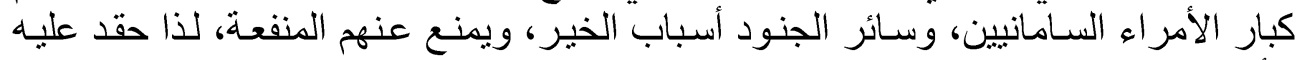

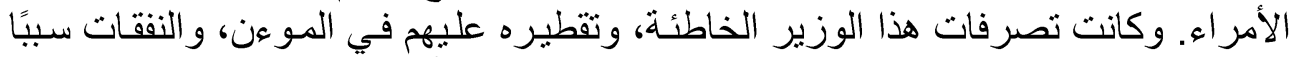

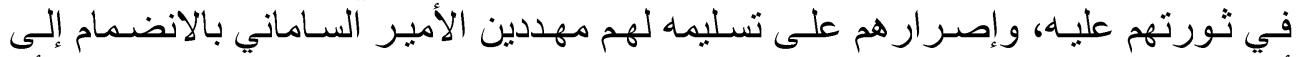

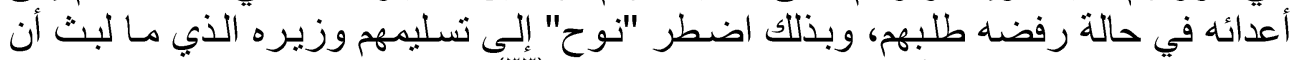

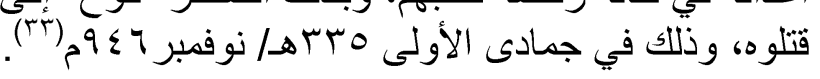




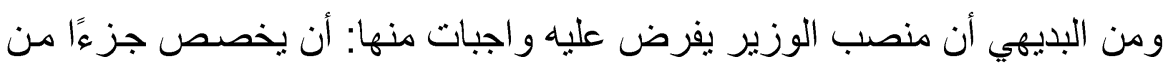

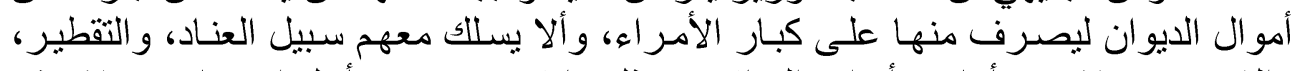

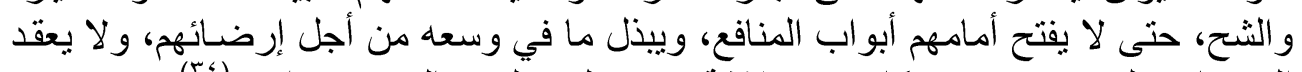

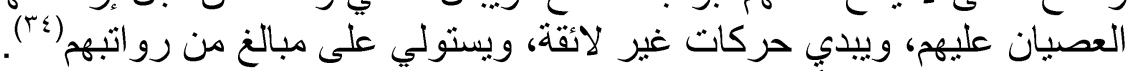

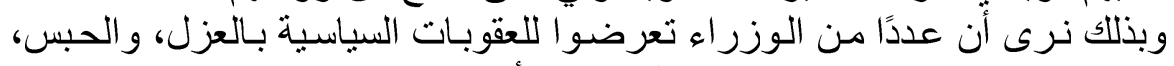

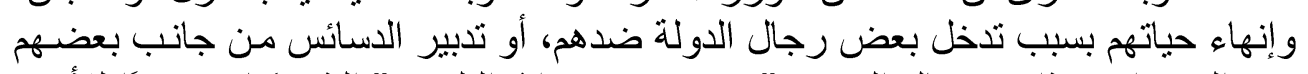

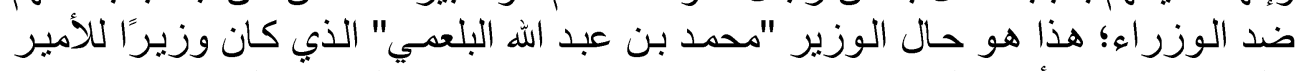

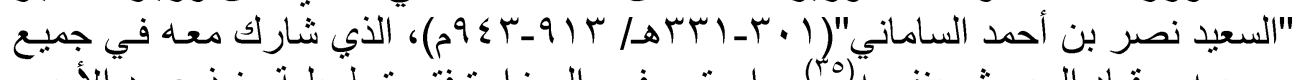

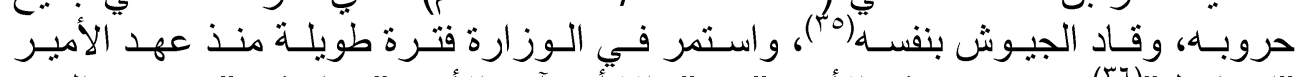

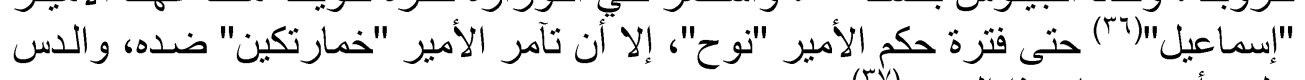

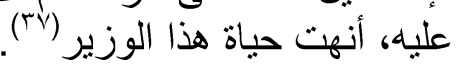
ويظهز هذا كذللك مع الوزير "أبو جعفر العتبي" وزير الأمير "عبد الملك بن نوح

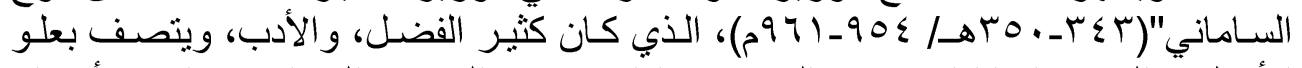

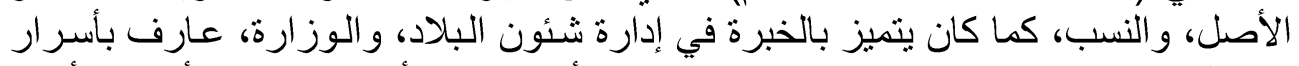

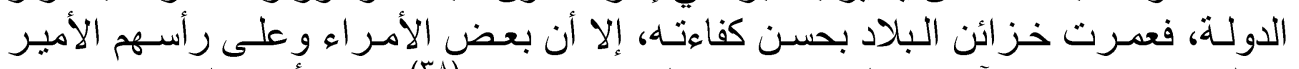

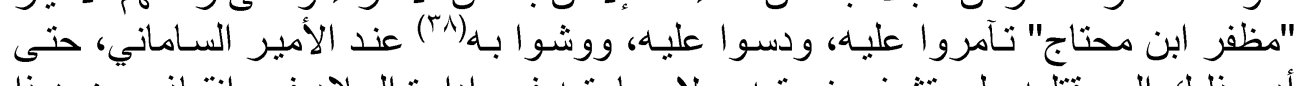

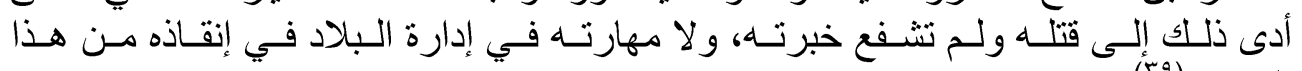

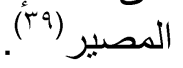

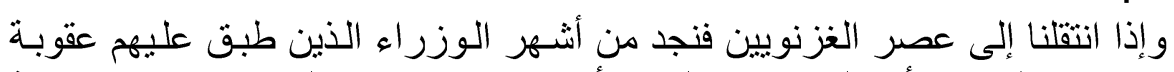

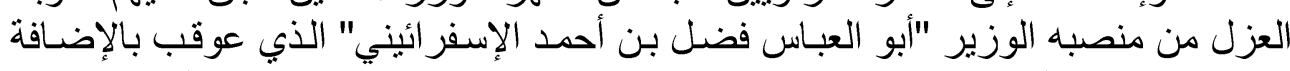

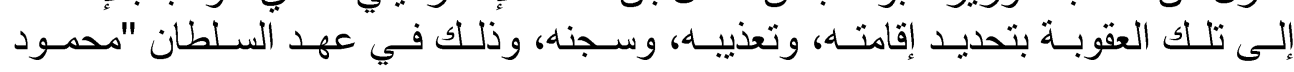

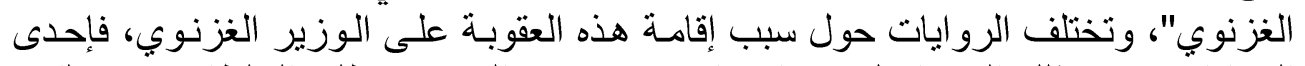

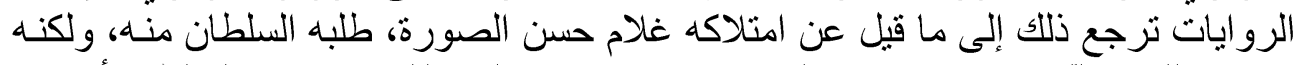

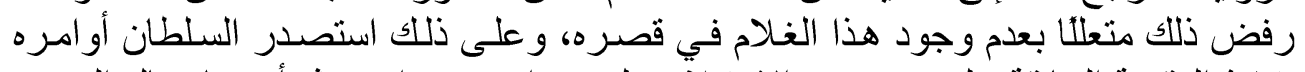

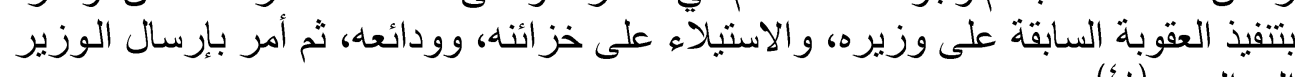

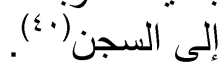

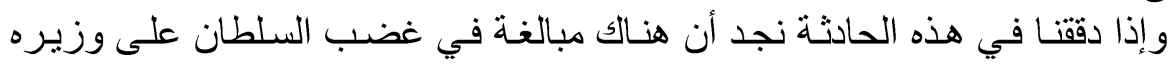

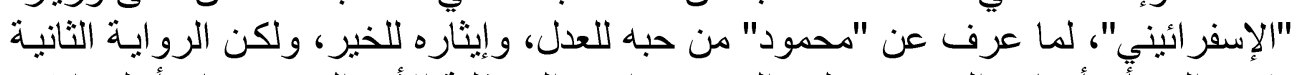

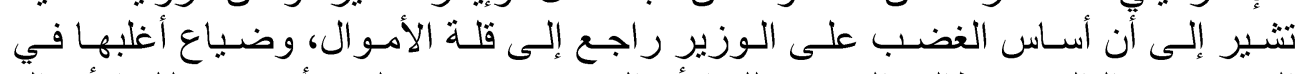

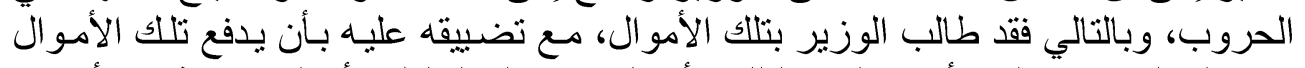

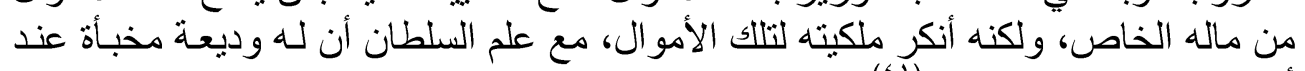

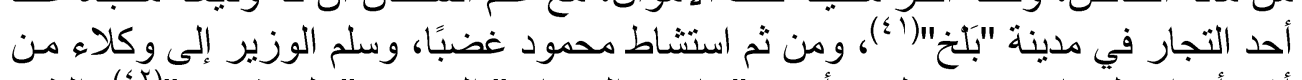

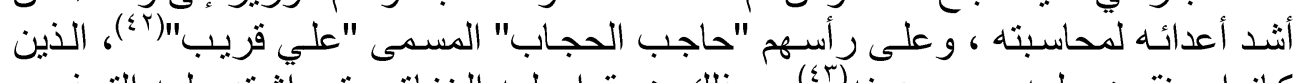

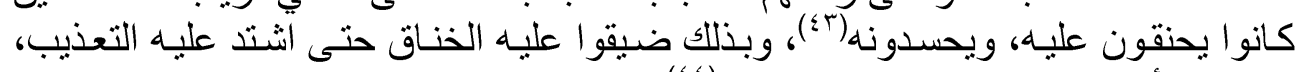

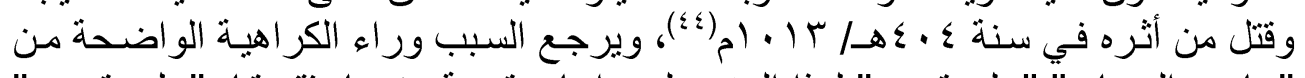

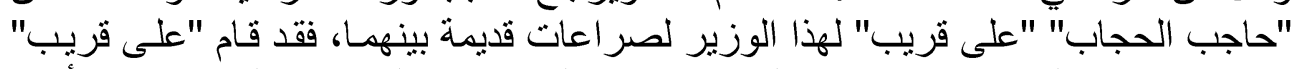

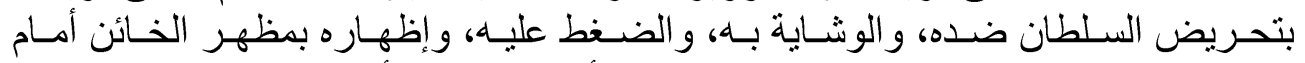

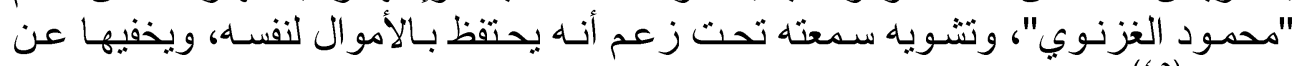




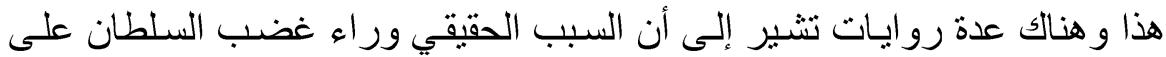

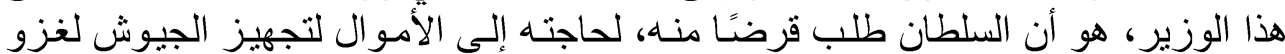

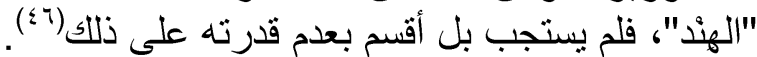

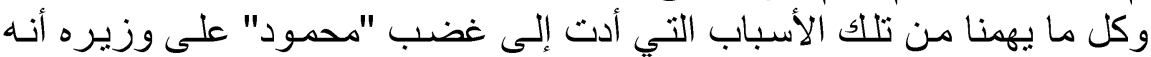

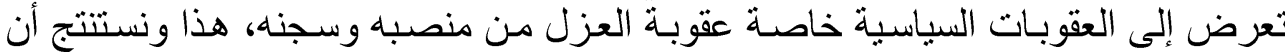

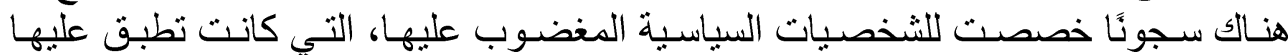

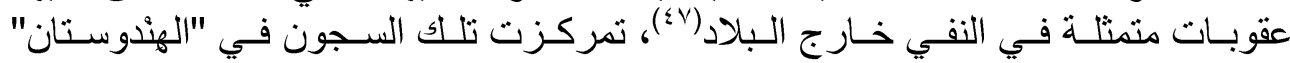
بــ"اللندّ".

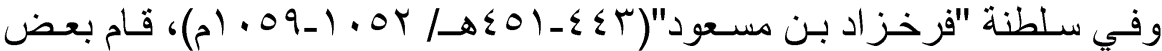

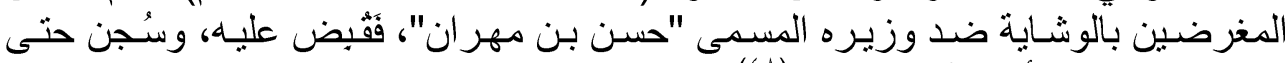

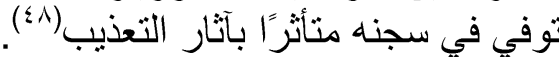

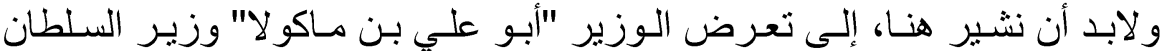

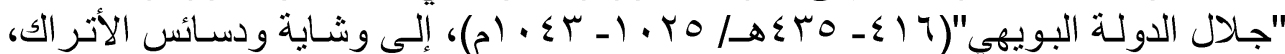

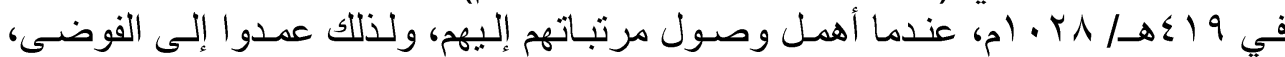

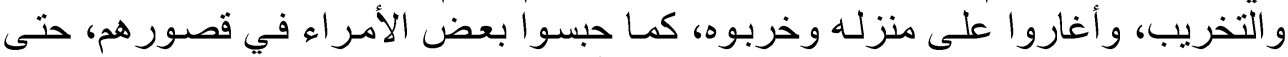

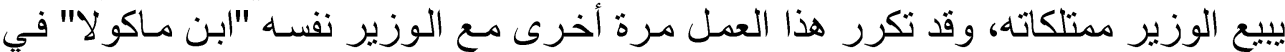

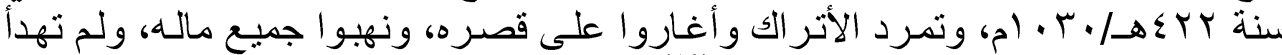

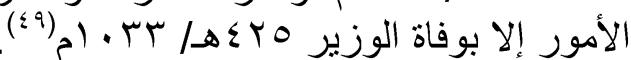

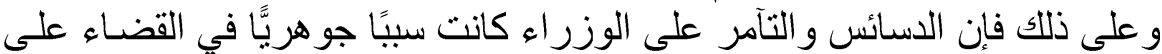

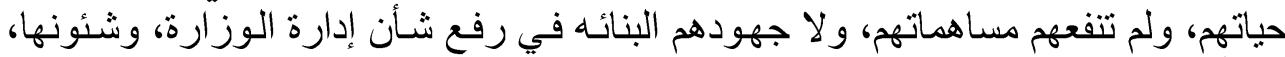

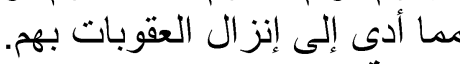
من أبرز العقوبات السياسية التي حلت بالوزر اءء عقوبة السجن، خاصـة في القرنين

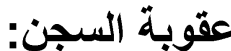

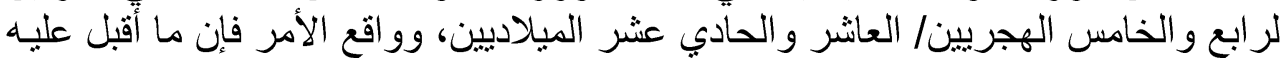

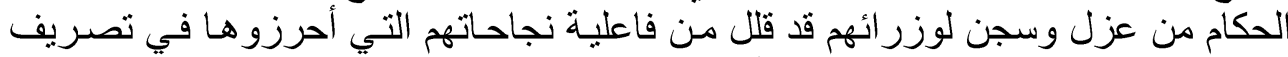

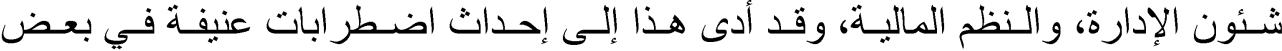

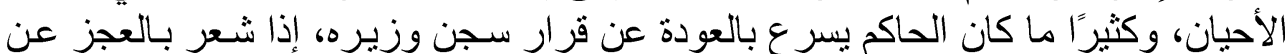

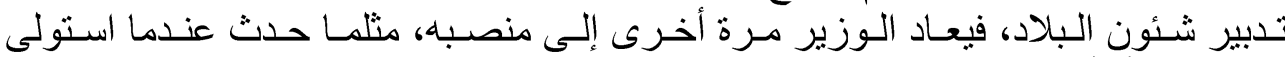

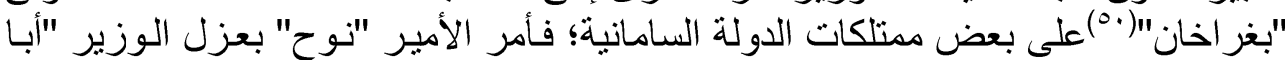

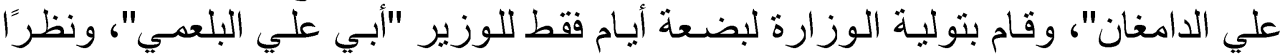

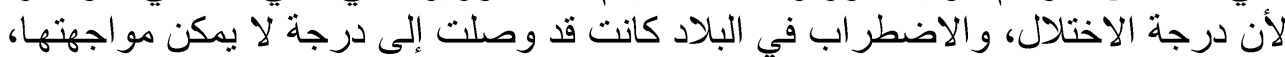

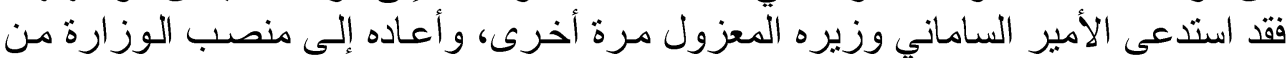
وكان الأمير قد أمر بمصـادرة أموال الوزير وممتلكاتـه ومحاسبته بكل الوسـائل جديد (01)

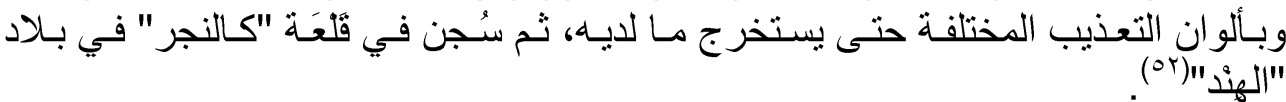

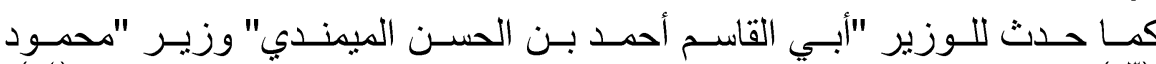

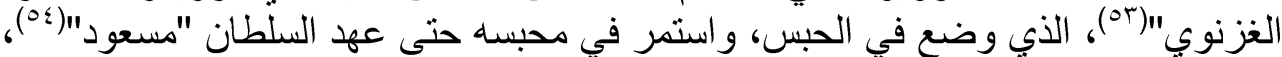

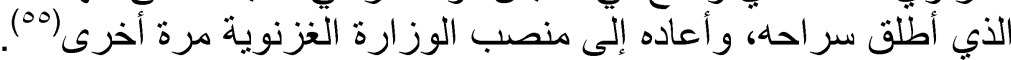




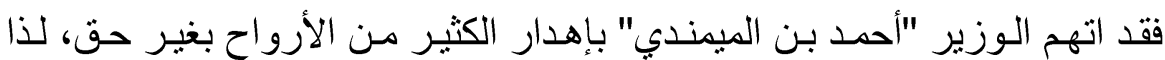

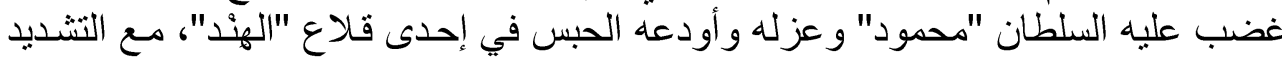

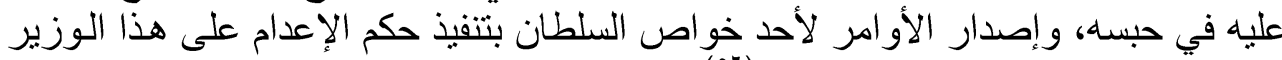

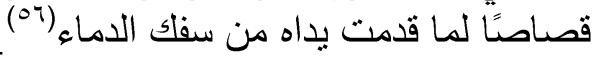

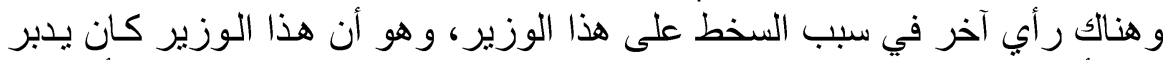

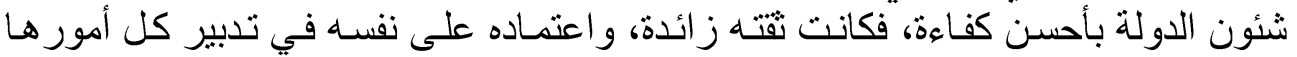

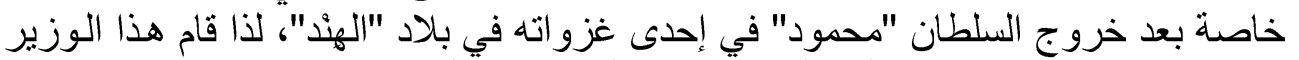

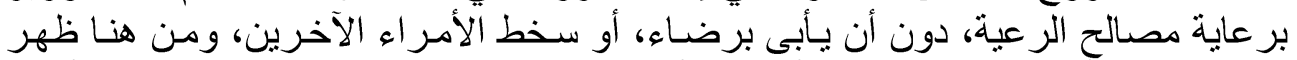

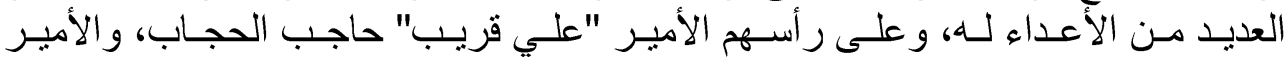

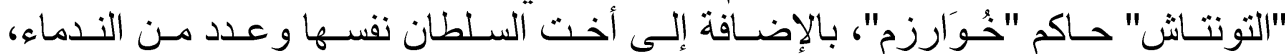

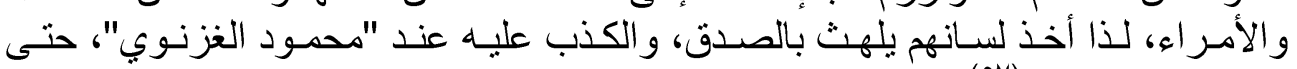

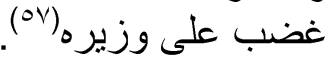

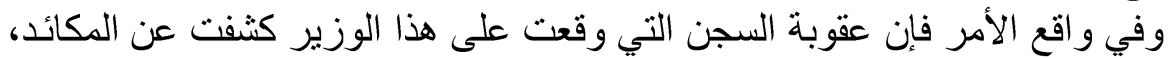

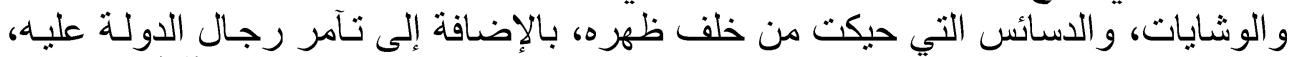

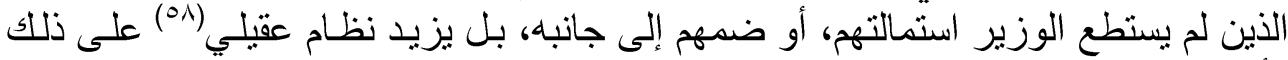

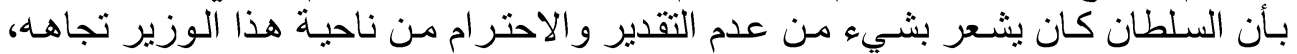

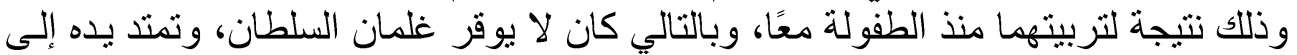

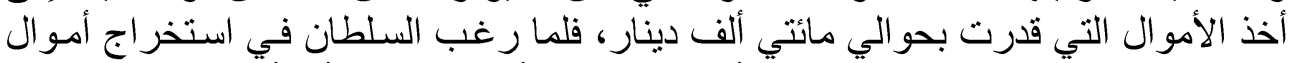

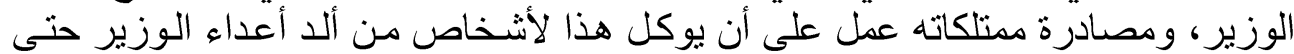

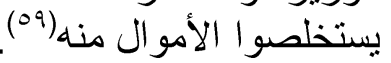

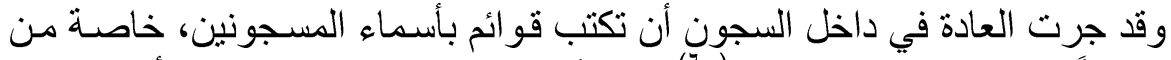

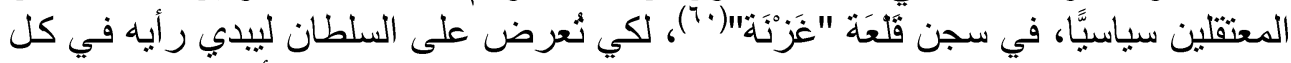

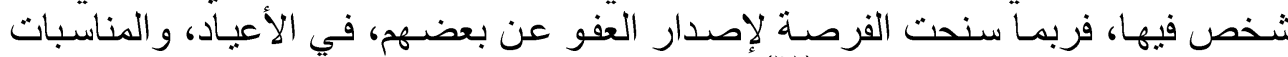

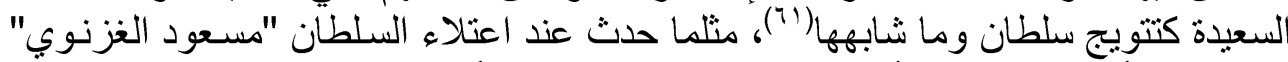

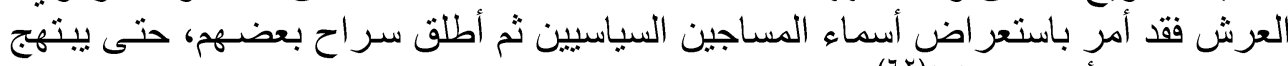

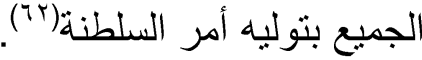

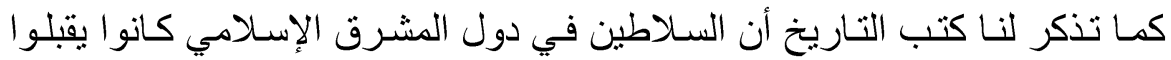

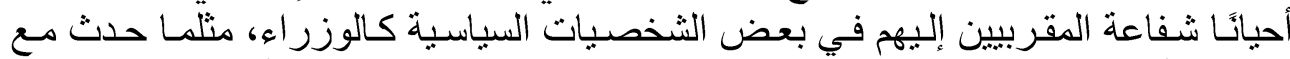

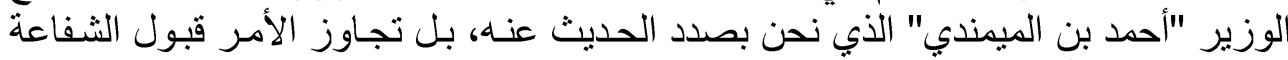

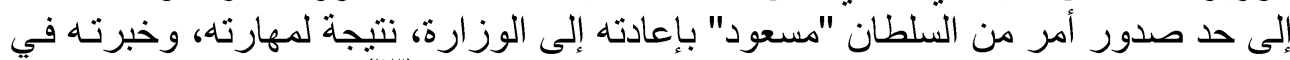

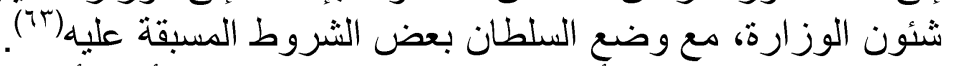

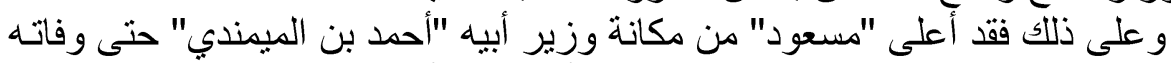

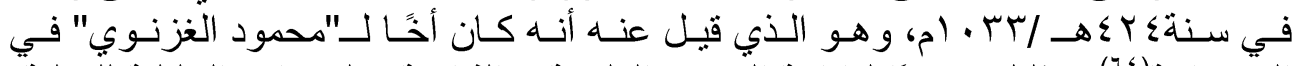

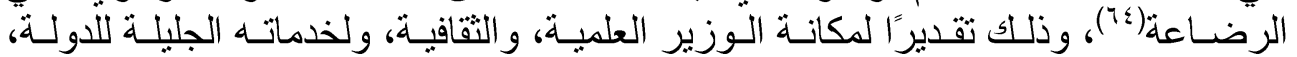

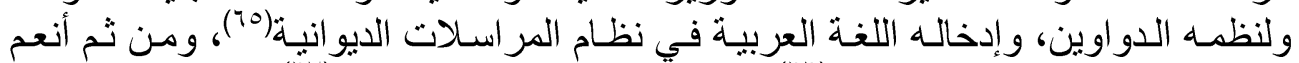

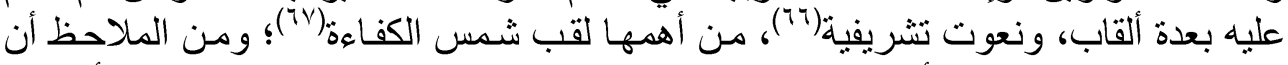

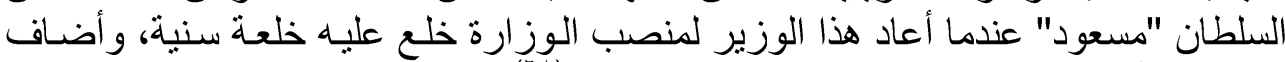

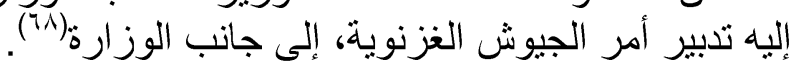

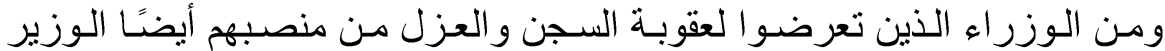

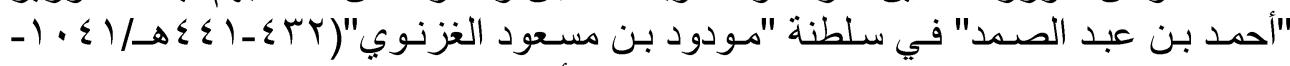

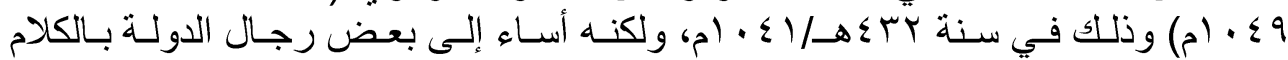




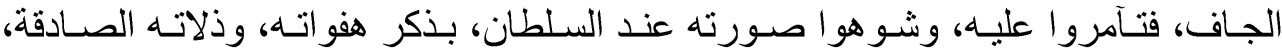

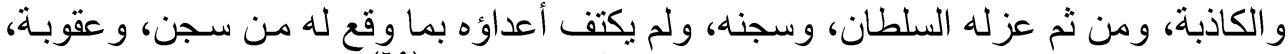

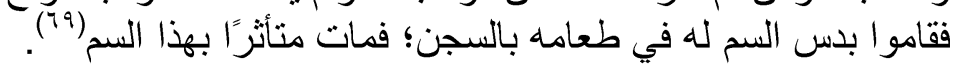

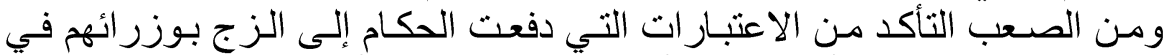

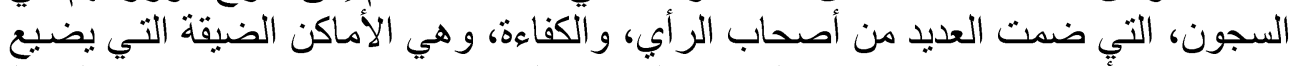

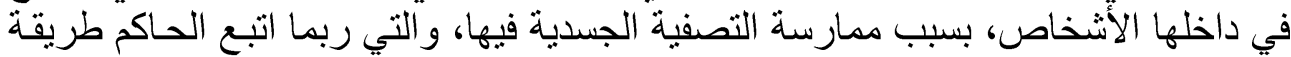

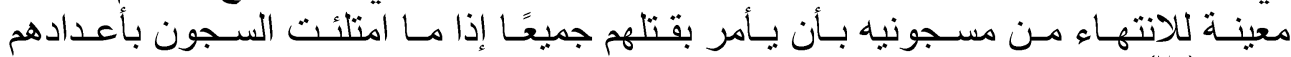

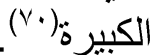
كما كان من المتبع إقامة الحر اسة المشددة على هذه المعتقلات في جميع الأوقات،

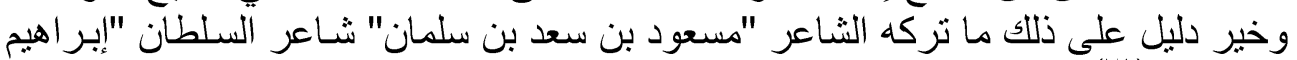

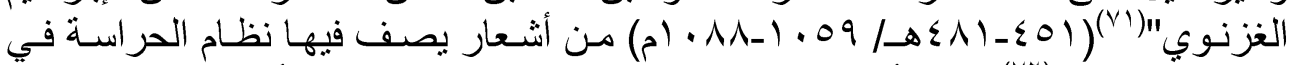

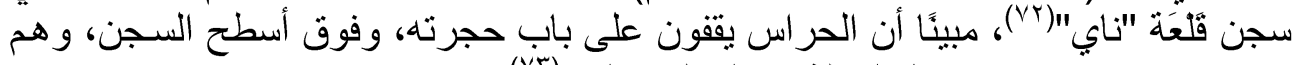

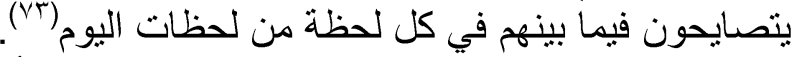

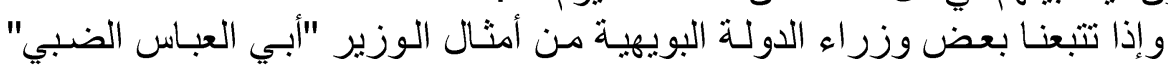

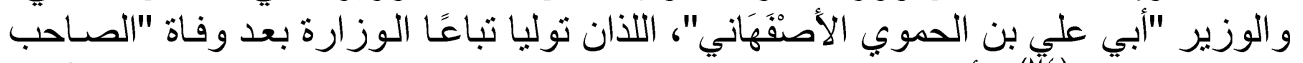

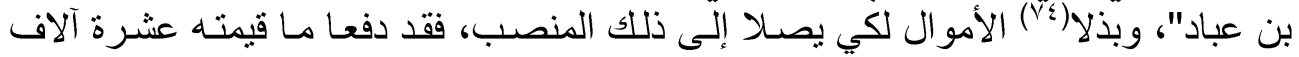

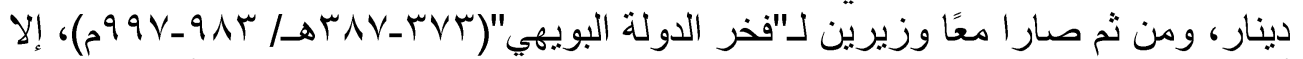

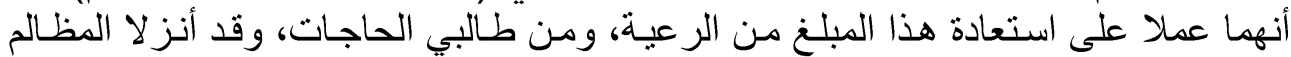

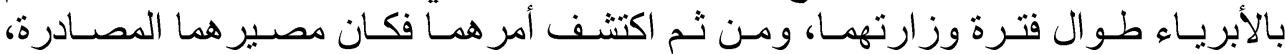

من العقوبات السياسية التي اتبعت على الوزر اءء في تلك الفترة سمل العينين، و التي

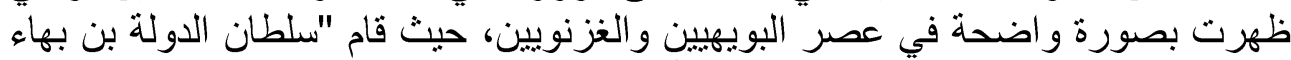

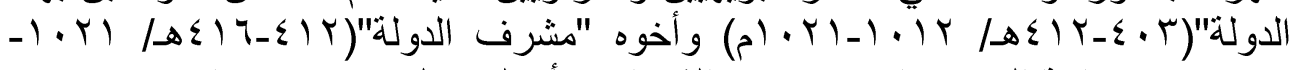

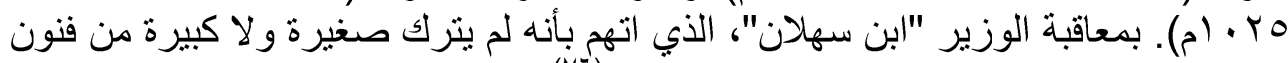

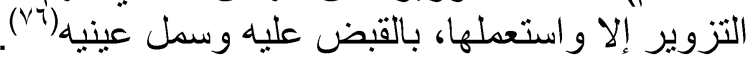

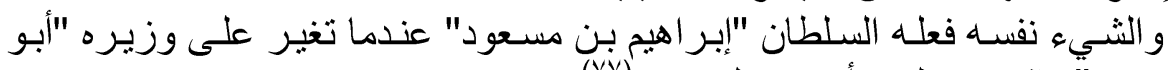

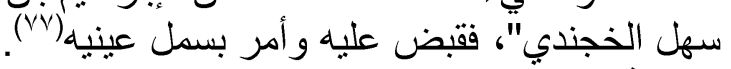
عقوبة الشنق : عني"

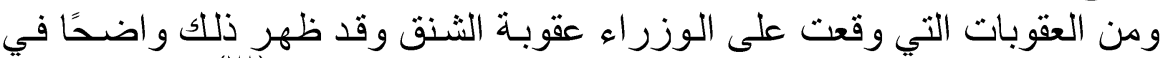

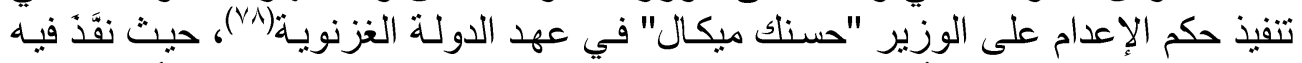

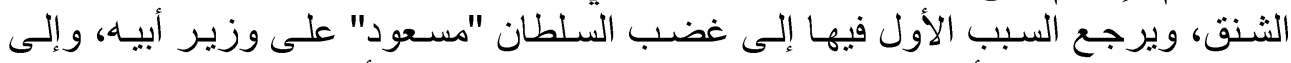

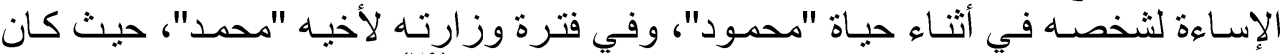

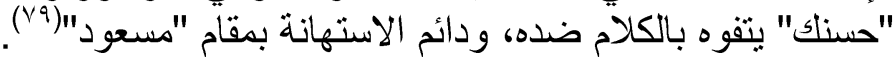

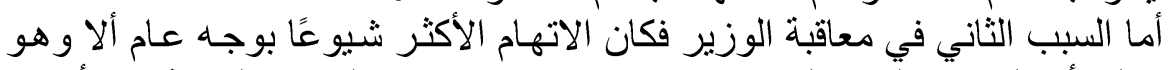

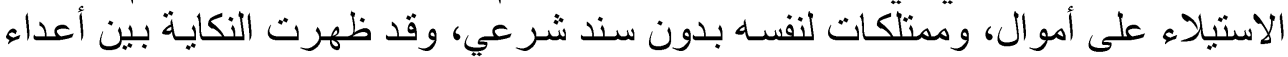
"حسنك"، لدرجة التشفي فيه من عدوه اللدود الذي سبق وأن ذاق الذل و والهوان على يديـه، 


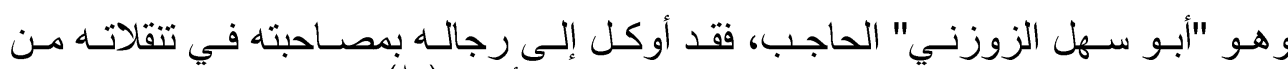

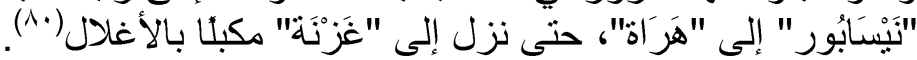

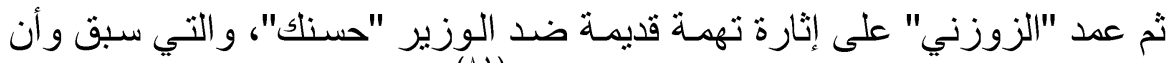

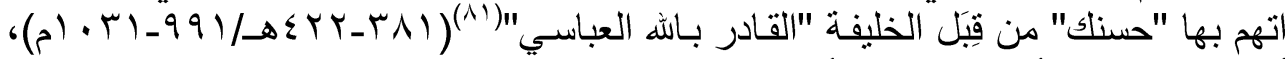

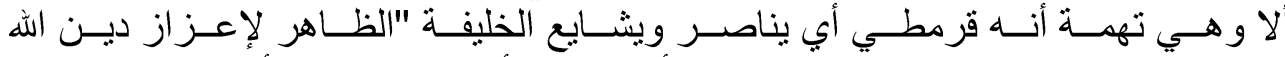

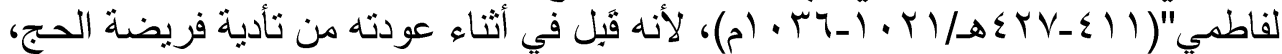

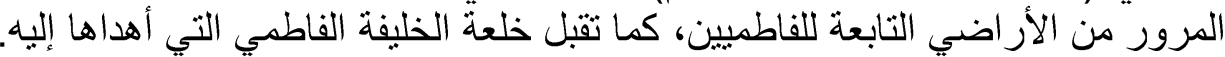

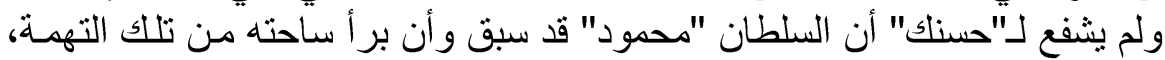

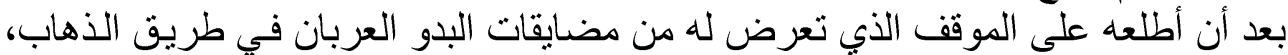

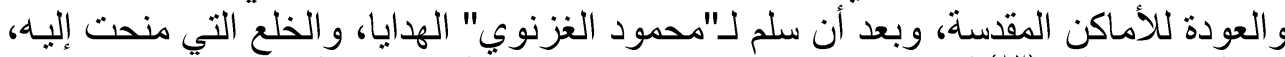

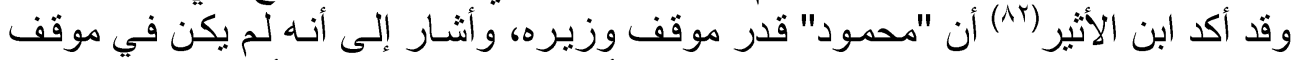

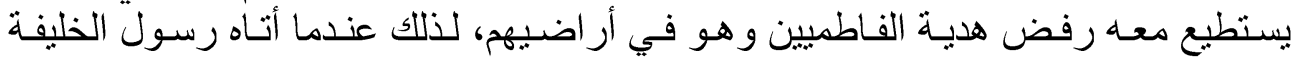

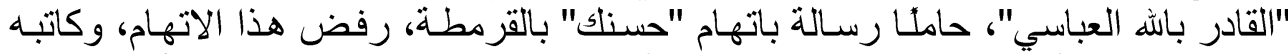

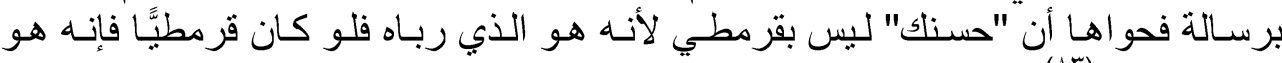

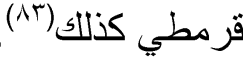

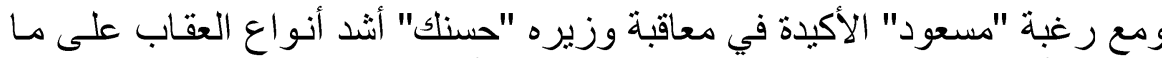

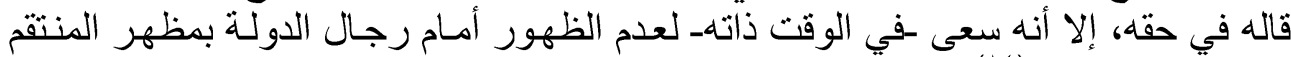

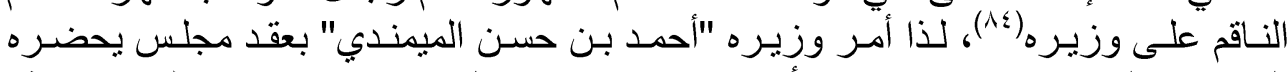

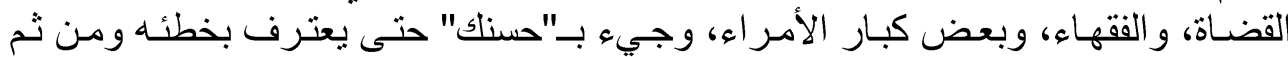

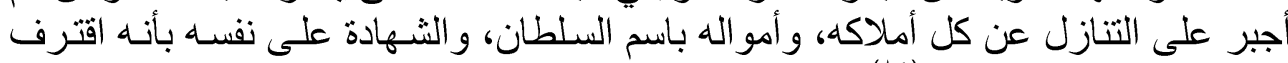

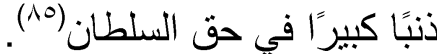

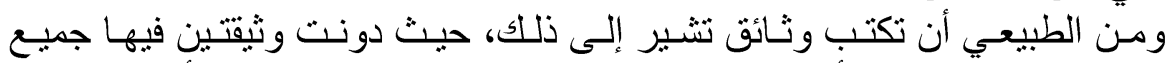

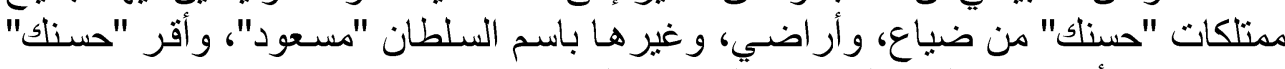

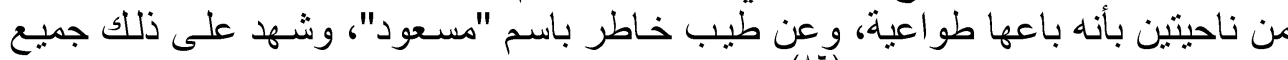

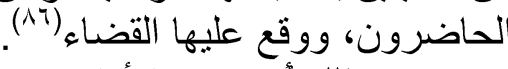

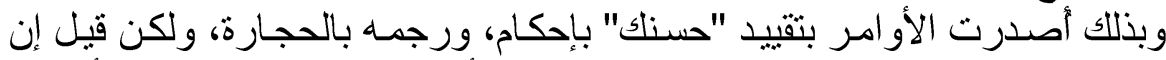

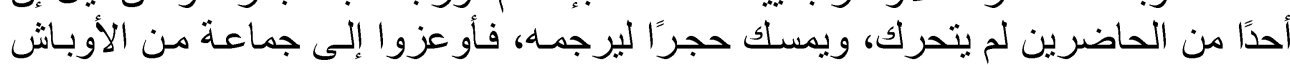

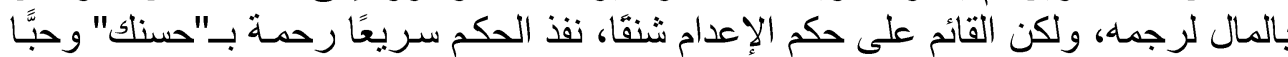

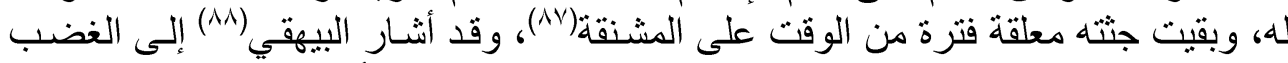

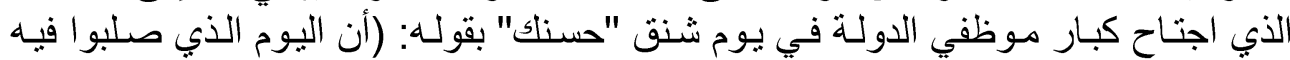

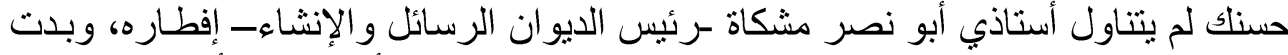

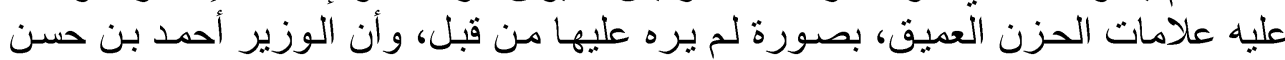

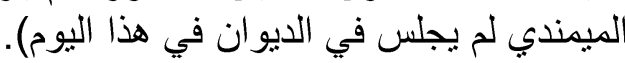

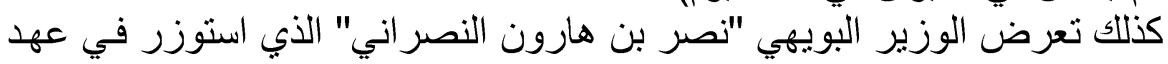

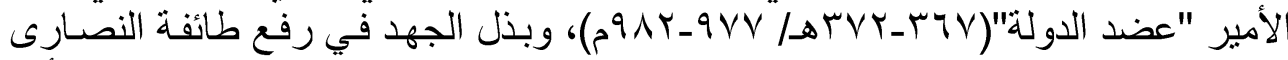

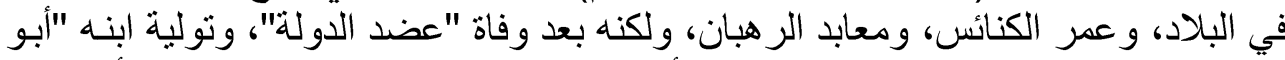

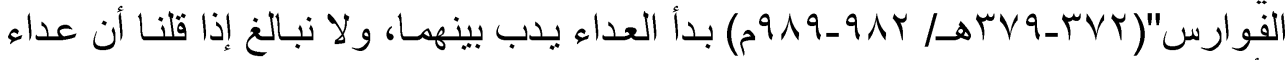

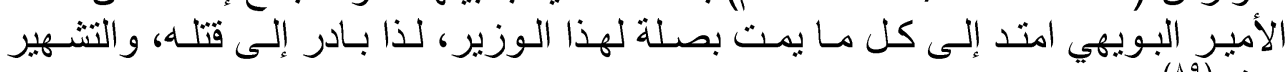




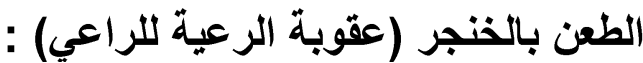

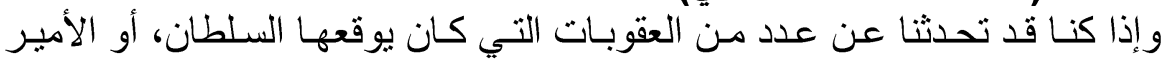

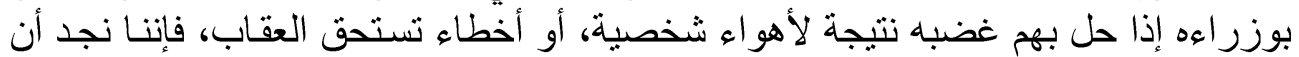

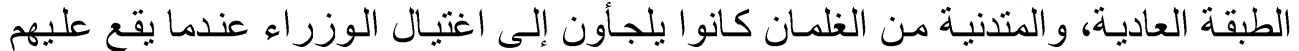

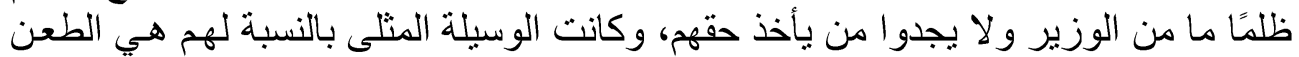

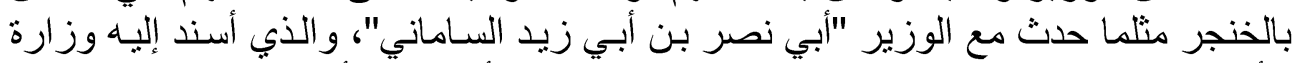

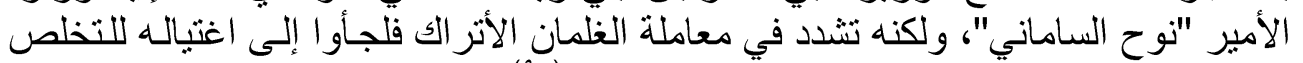

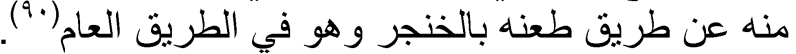

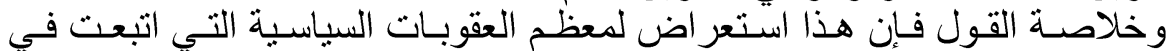

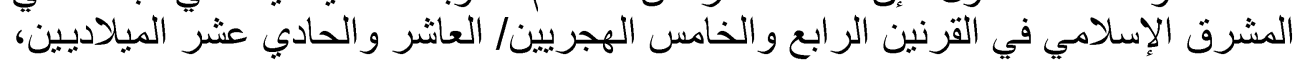

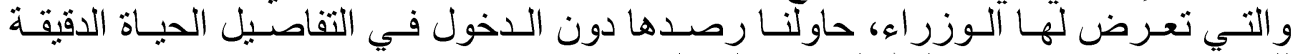

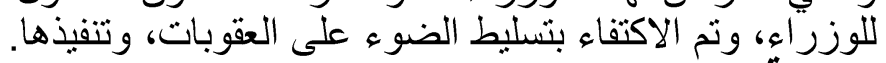

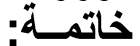

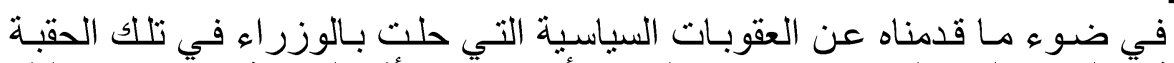

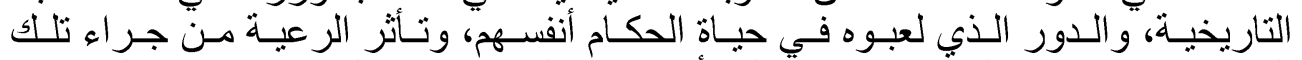

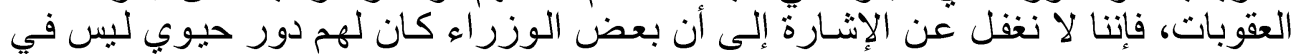

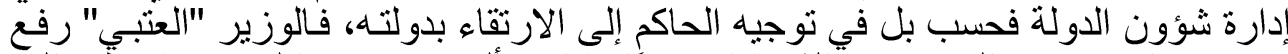

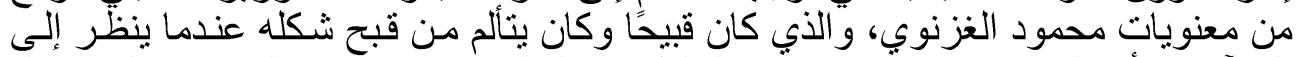

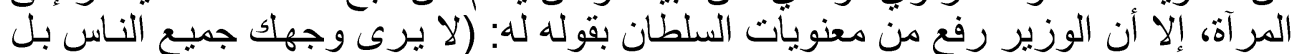

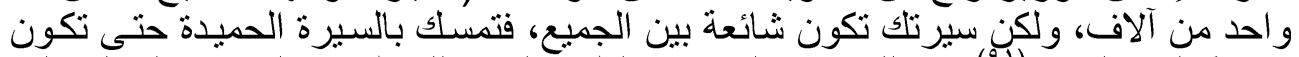

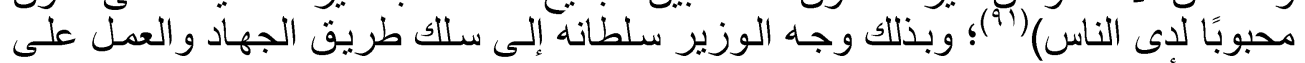

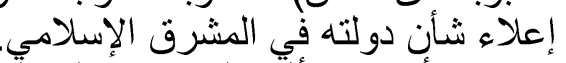

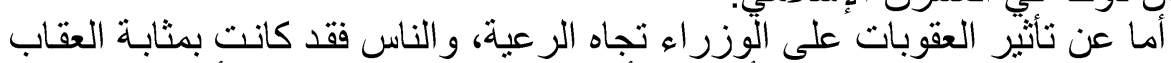

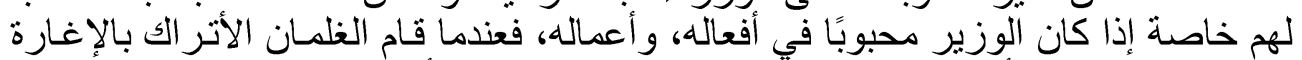

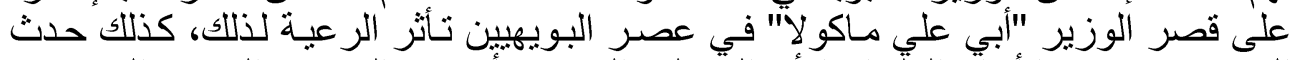

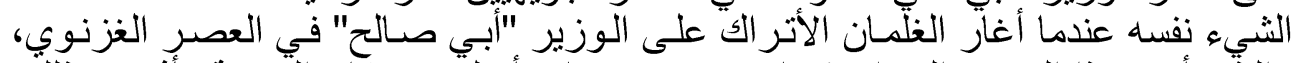

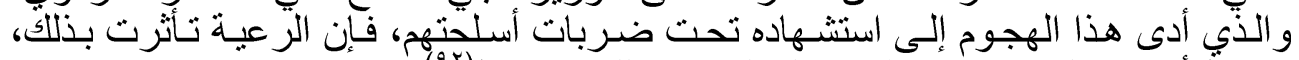

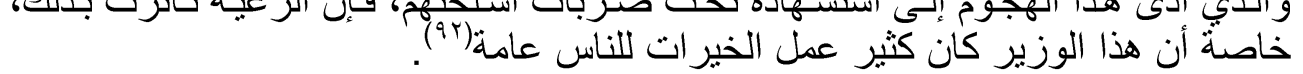

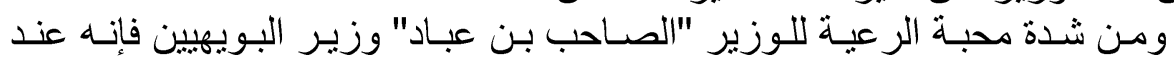

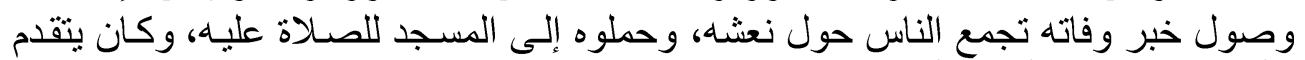

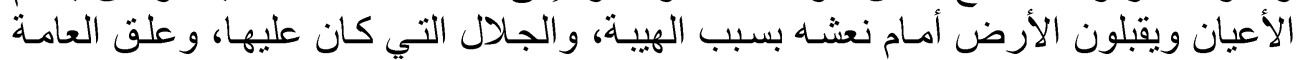

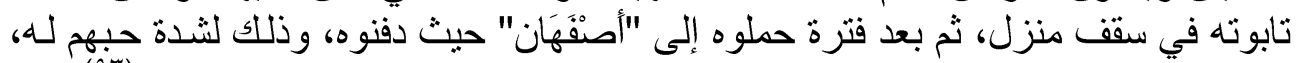

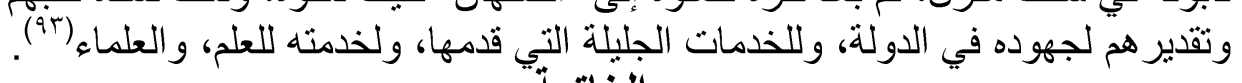

\section{الخاتمة}

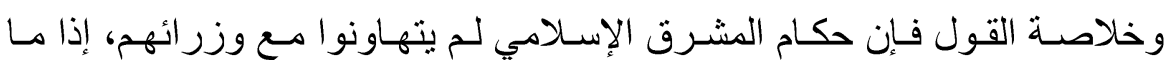

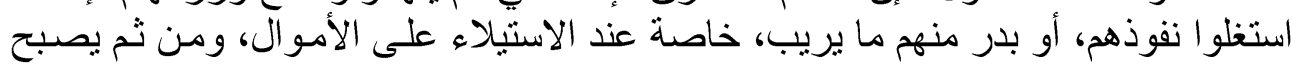

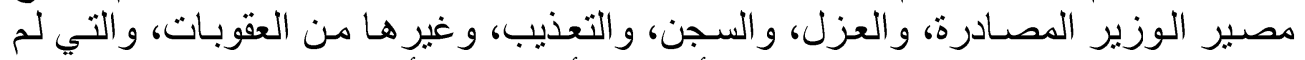

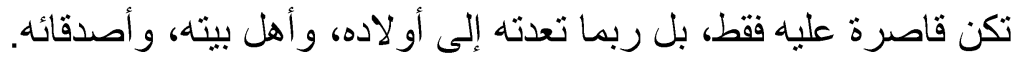

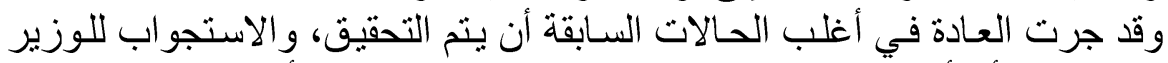

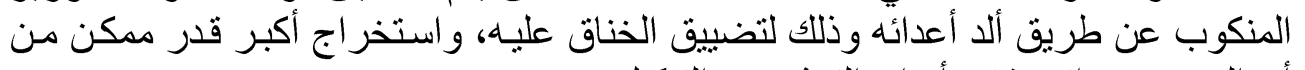

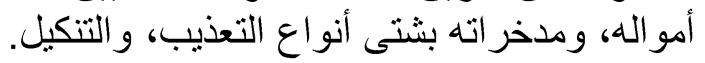




\section{Abstract \\ Political sanctions for the ministers of the Islamic East \\ In the fourth and fifth centuries $\mathrm{AH}$ \\ By Afraa Azem Alyan Al Sharari}

This study aims to shed light on the penalties that have befallen some ministers, including confiscations, isolation, imprisonment, flogging, and other types of abuse and persecution, and the extent of what is returned to public life as a result of these measures while showing the role that the most famous of these ministers played in the parish life and the life of rulers in their countries both.

The research will also address the meaning of political sanctions and the types of political sanctions, and the sanction for determining residency. It will also deal with the impeachment sanction, sanction of imprisonment, and we will monitor the sanction for an act of blinding, the sanction of hanging, and stabbing with the dagger.

Finally, in conclusion, we present the most important results we have reached.

Key words: confiscations, isolation and imprisonment, abuse and persecution, the significance of political sanctions.

$$
\begin{aligned}
& \text { الإهوامشي }
\end{aligned}
$$

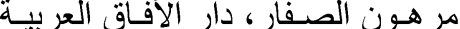

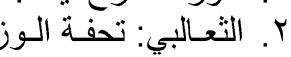

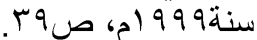

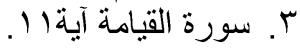

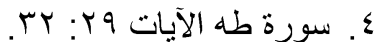

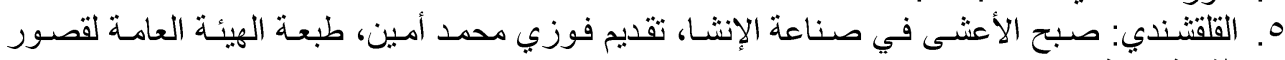

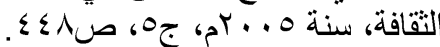

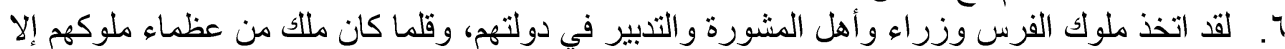

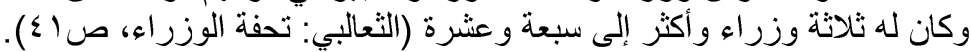

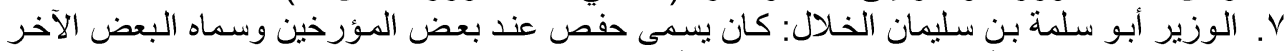

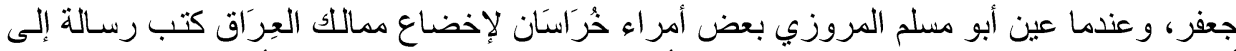

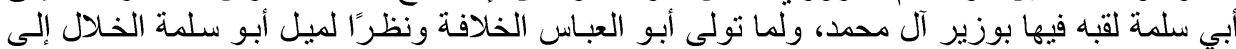

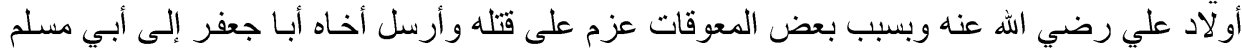

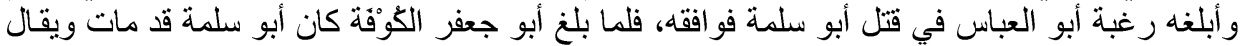

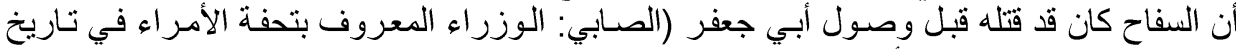

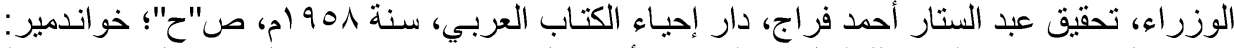

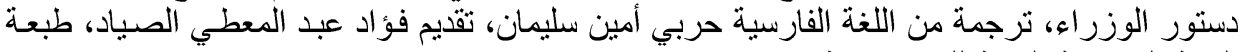

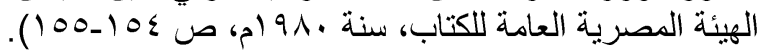

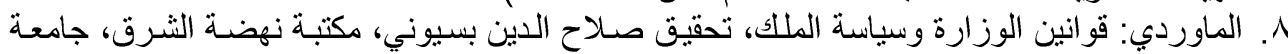

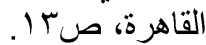

$$
\begin{aligned}
& \text { 9. وزير التتفيذ هو الذي يكون وسيطا بين الإمام والرعايا معتددًا على رأي الإمام وتدبيره (الصابي: تحفة }
\end{aligned}
$$

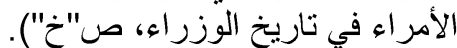

$$
\begin{aligned}
& \text { • ا. . الماوردي: الأحكام السلطانية والؤلايات الدينية، الأحكام السلطانية والولايات الدات الدينية"، طبعة دار الكتب }
\end{aligned}
$$

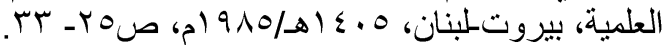

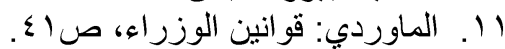


r ا. . يتعين على وزير التتفيذ أن لا يغيب عن موضع الملك، لأنه يحتاج إلى مشورته ومر اجعته في أكثر

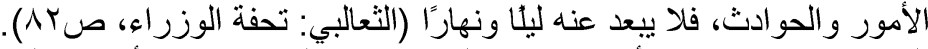

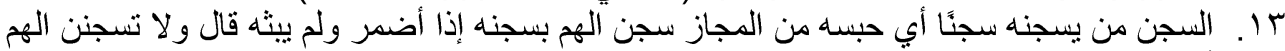

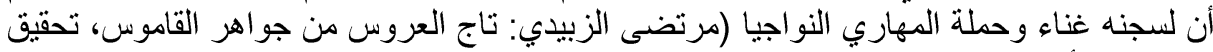

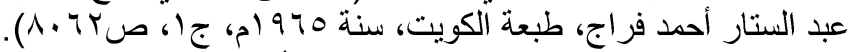

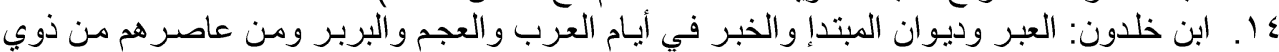

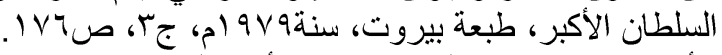

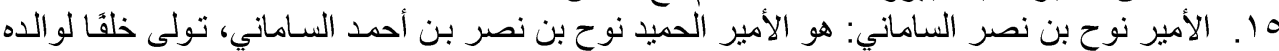

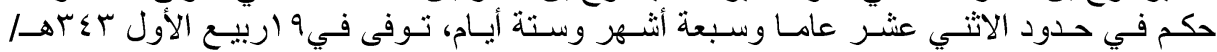

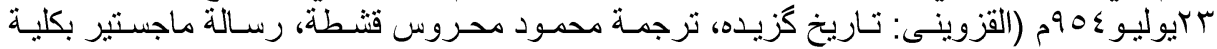

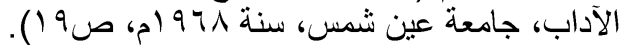
17 ا. ميرخو اند: روضة الصفا في سيرة الأنبياء و الملوك ولك والخلفاء، ترجمة من الفئة الفارسية أحمد عبد القادر

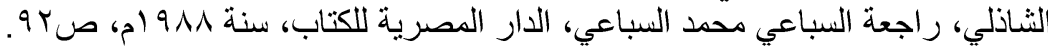

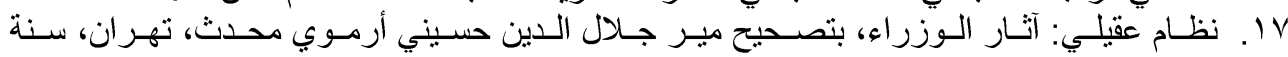

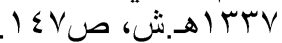

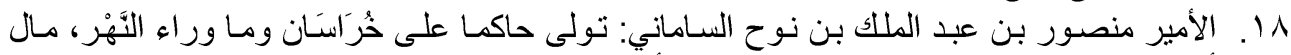

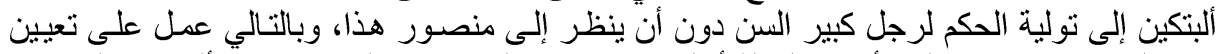

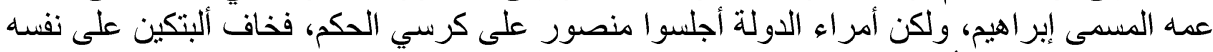

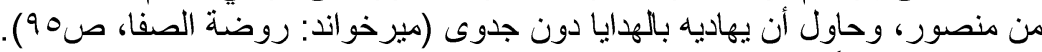

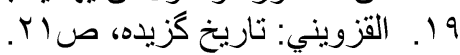

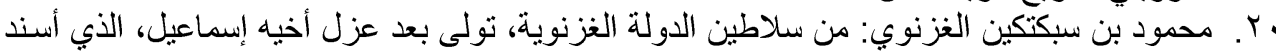

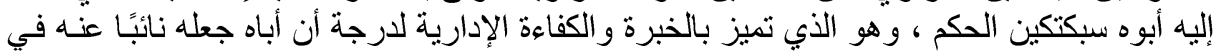

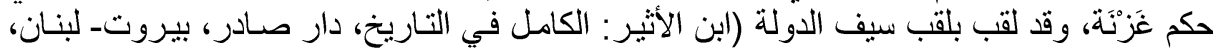

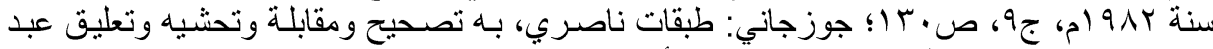

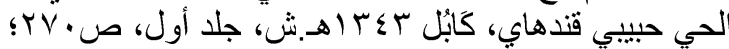

Bosworth: "The titulature of the early Ghaznavids Oriens" (Leiden, i 97 r)، p. ${ }^{10}$, Nazim M: "The life and the time of soltan Mahmoud of Ghazn" eith of arc ward by the late sir Tomes Arnold, (Combridge, 19r1), p.r·.

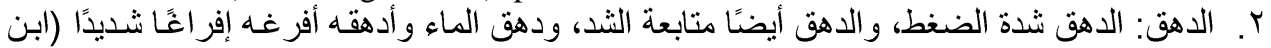

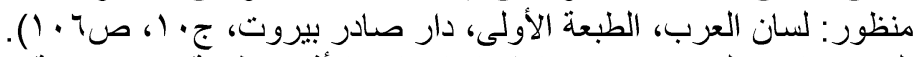

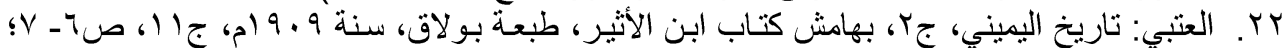

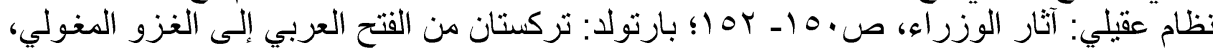

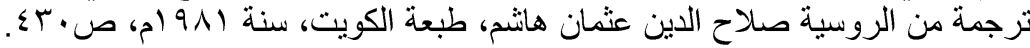

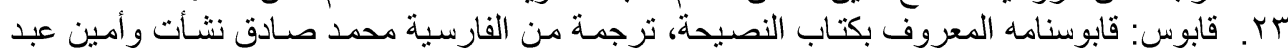

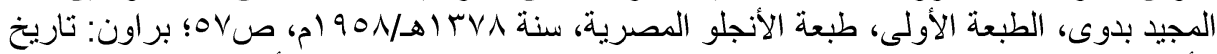

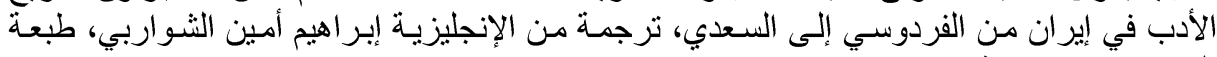

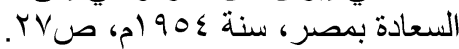

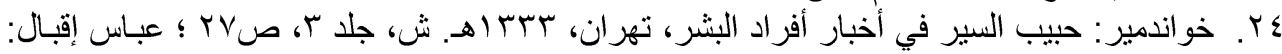

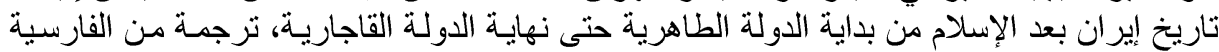

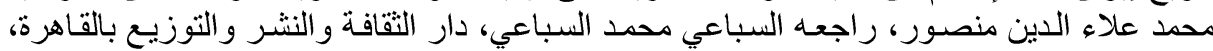

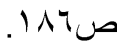

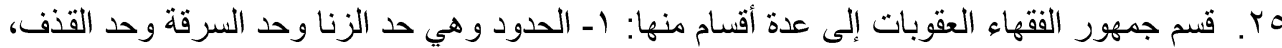

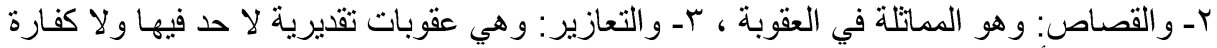

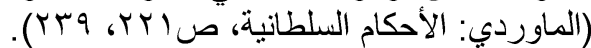

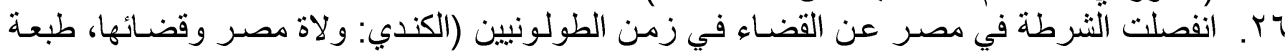

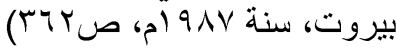




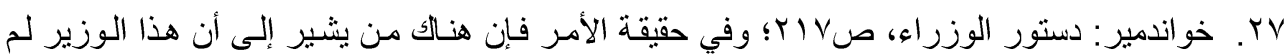

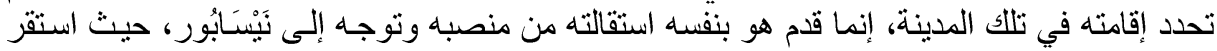

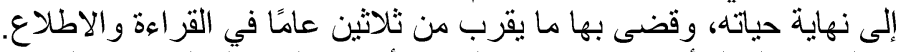

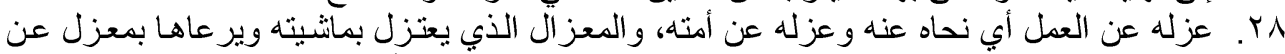

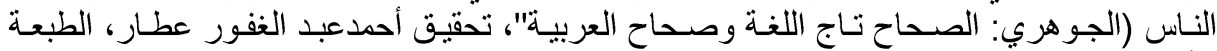

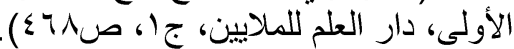

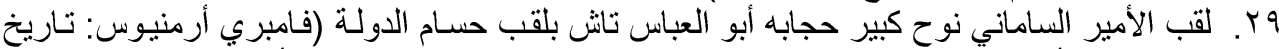

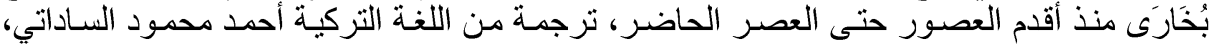

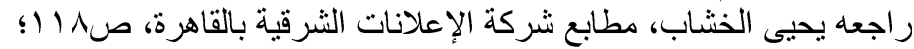
Frye R.N : "Bukhara the Medieval Achievement"،p. • (London, 1970).

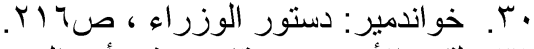

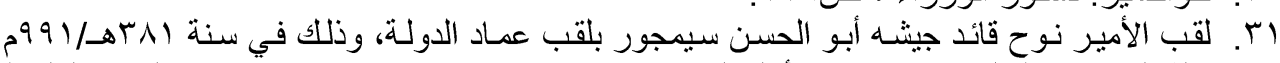

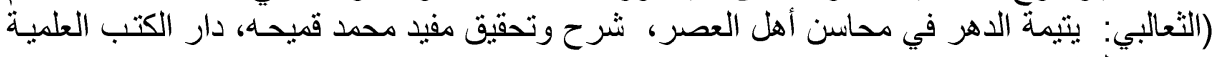

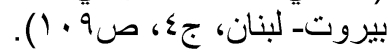

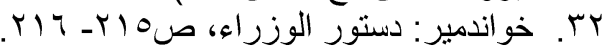
rr.

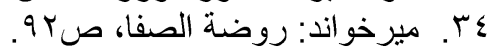

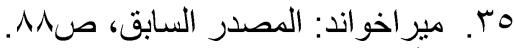

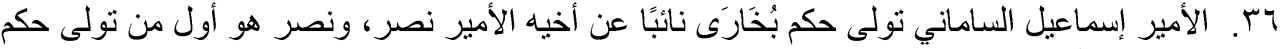

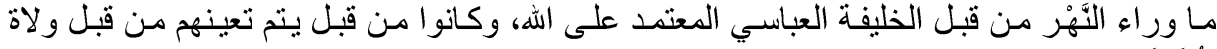

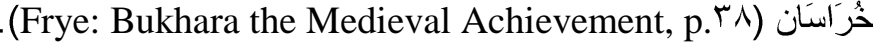

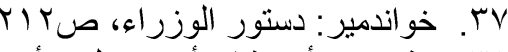

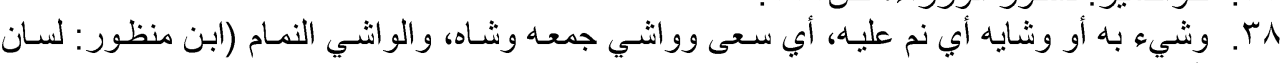

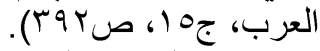

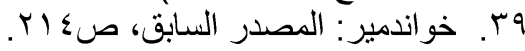

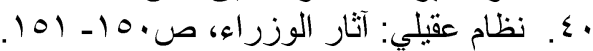

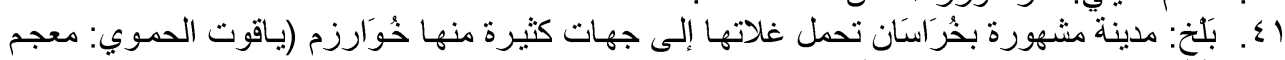

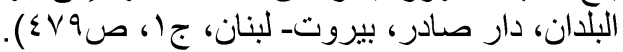

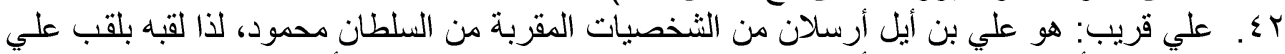

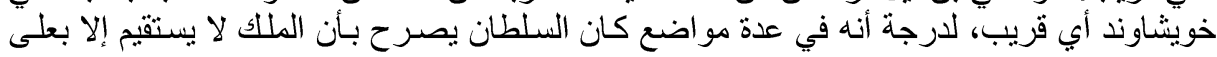

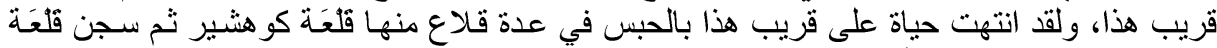

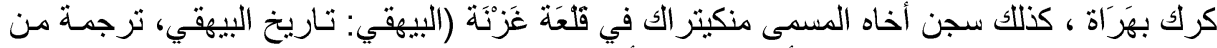

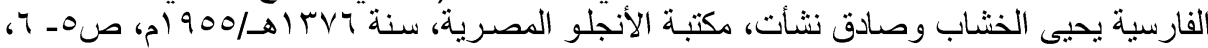

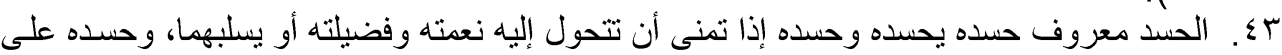

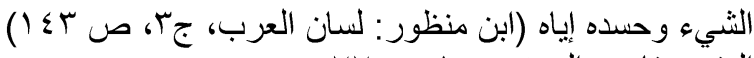

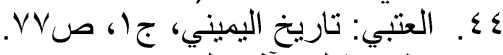

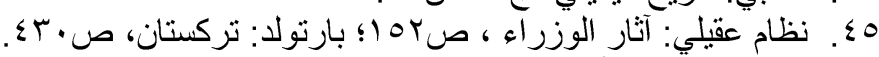

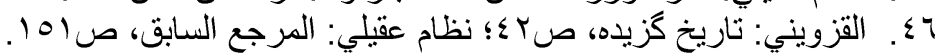

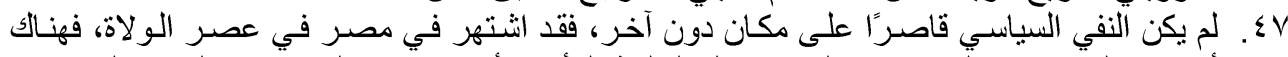

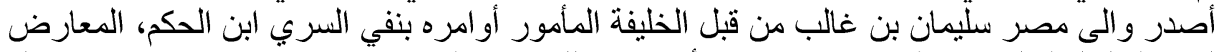

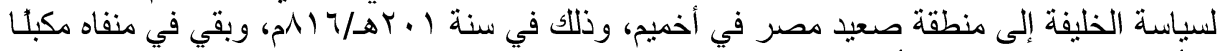

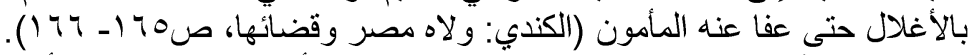

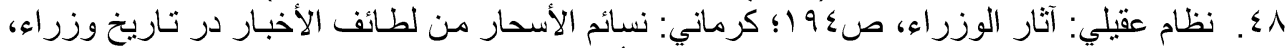

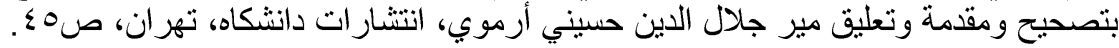

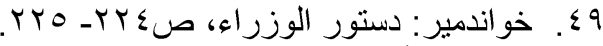

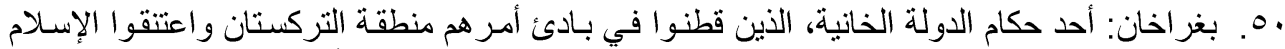

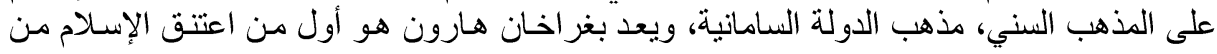




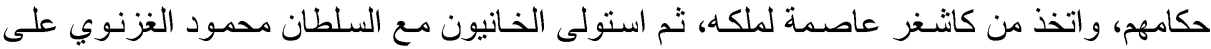

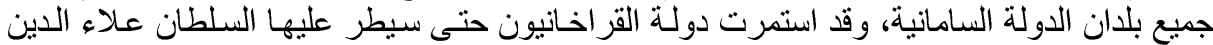

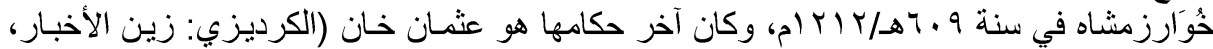

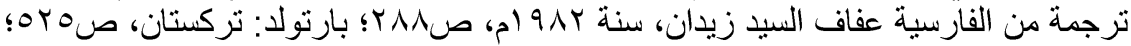

Howorth: "The Northern Frontages of China Afrasyab Turks"، Journal of the Royal Asiatic

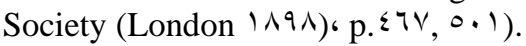

$$
\text { إن }
$$

Bosworth: The Ghaznavids their empire in Afghanistan and Eastern Iran P.P. $\cdot \cdot,,^{\prime}$ ).

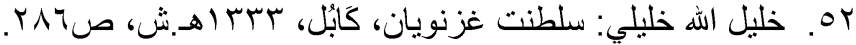

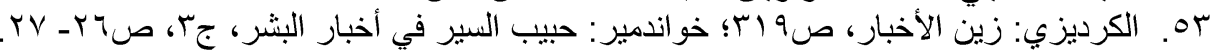

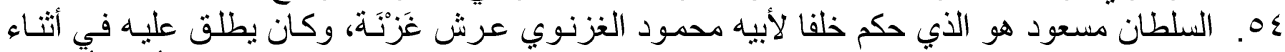

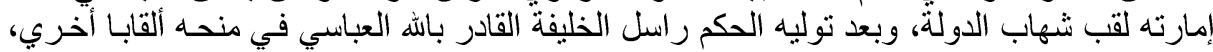

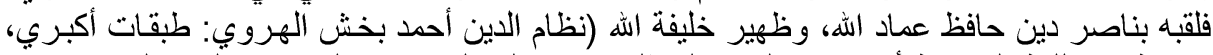

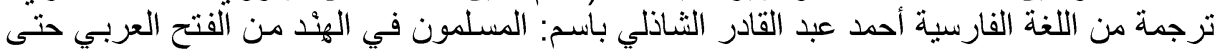

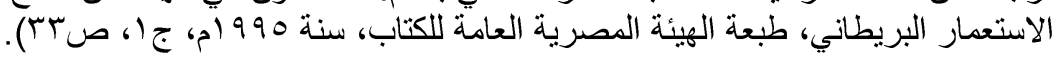

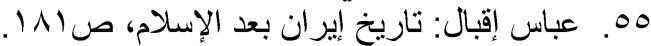

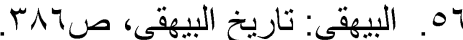

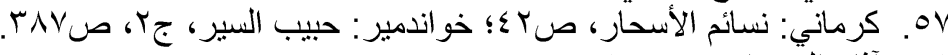

99 Bosworth CE: The Ghaznavids their empire in (Edinburgh, 197r)เp.p $\vee \cdot-\vee$ l.

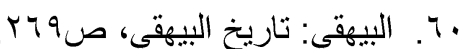

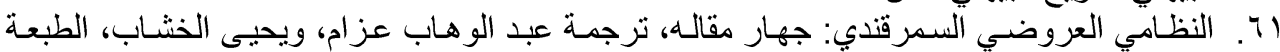

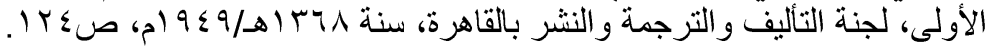

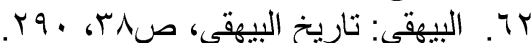

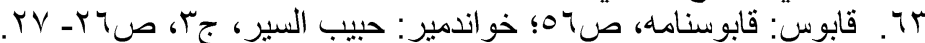

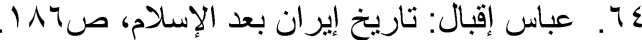

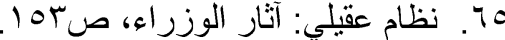

77. Nazim: the Life and the time, P. 1 个.

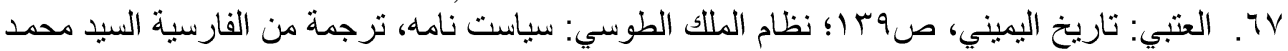

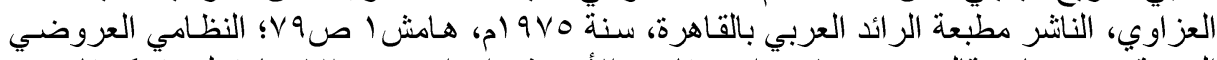

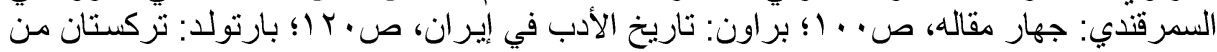

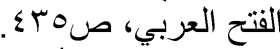

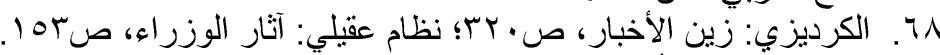

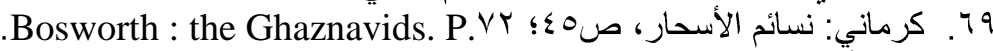

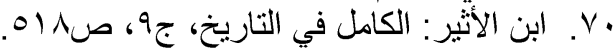

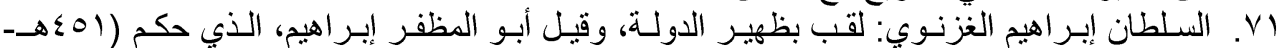

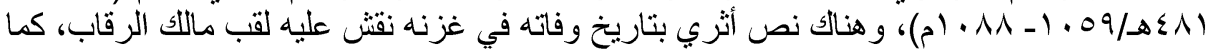

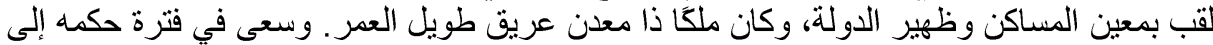

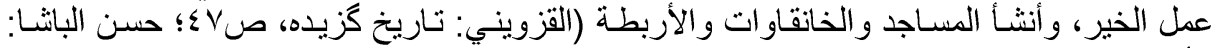

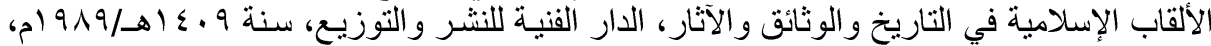

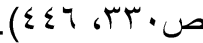
LY

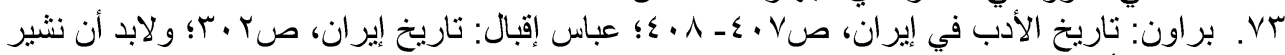

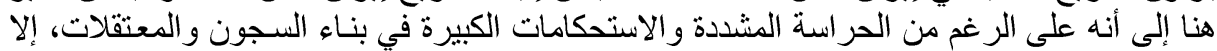




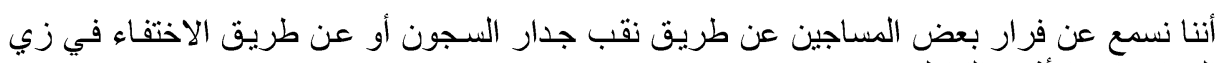

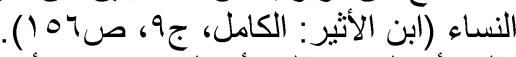

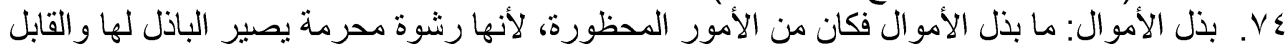

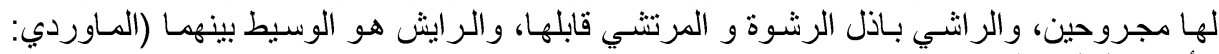

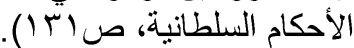

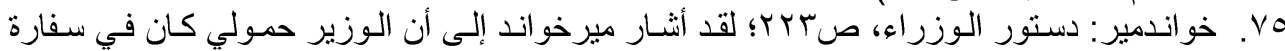

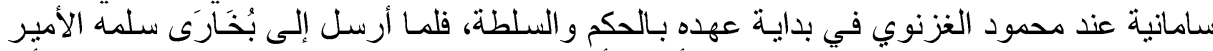

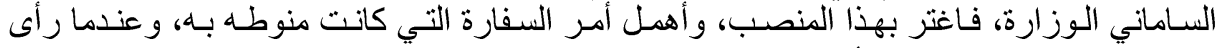

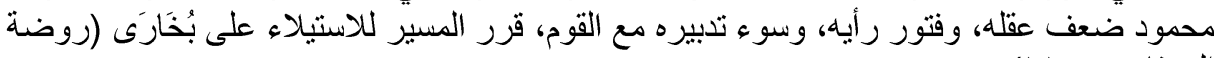

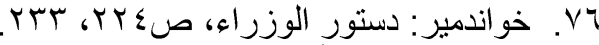

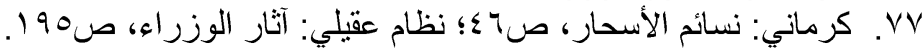

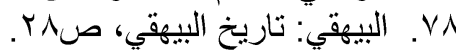

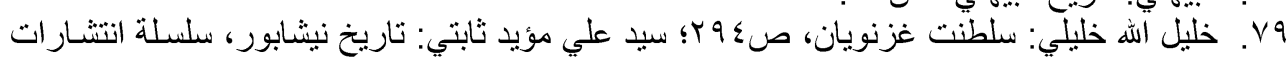

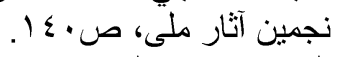

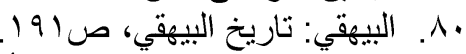

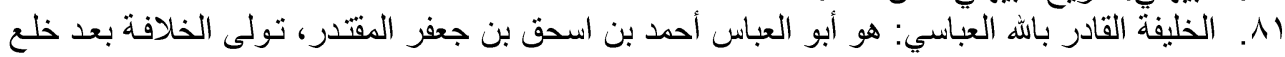

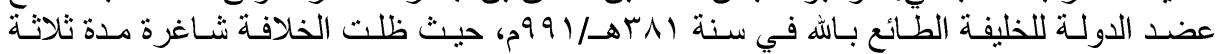

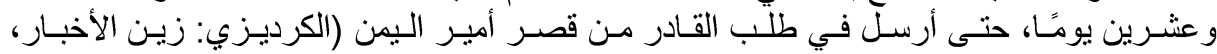

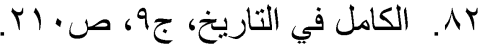

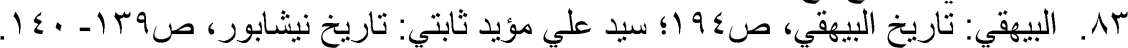

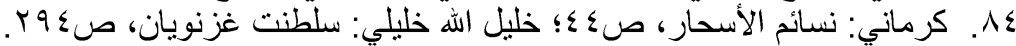

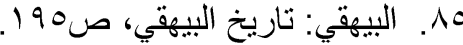

Bosworth: The Ghaznavids their empire in Afghanistan and Eastern Iran.P.Y

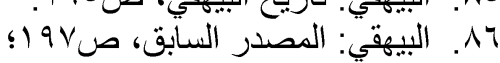

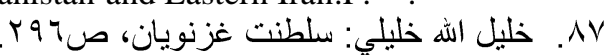

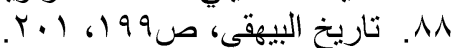

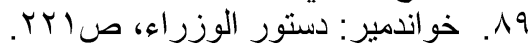
.9.

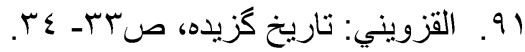

r r المصـادر والمـراجع

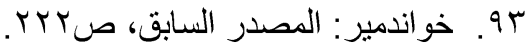

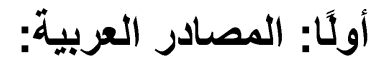

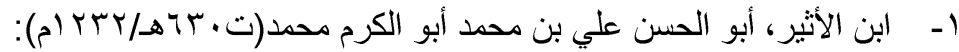

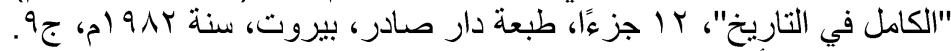

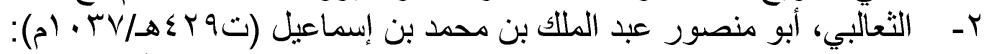

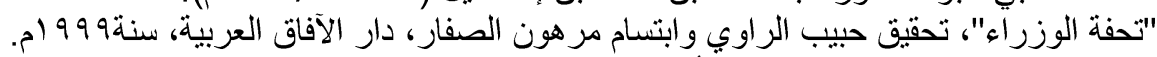

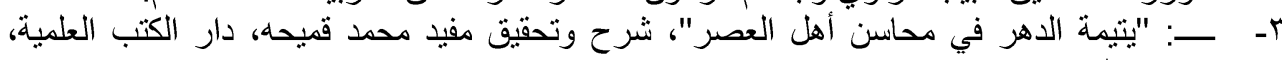

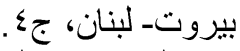

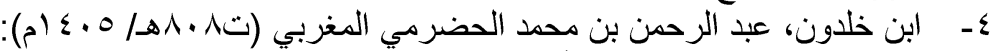

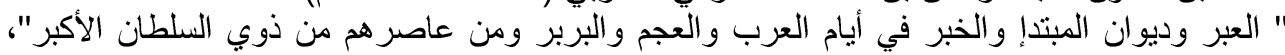

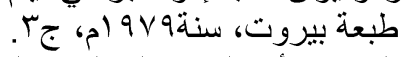

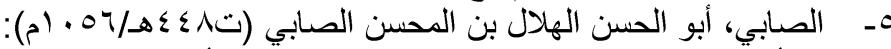

"تحفة الأمراء في تاريخ الوزراء"، تحقيق عبد الستار أحمد فراج، طبعة داهي دار إحياء الكتب العربية، سنة

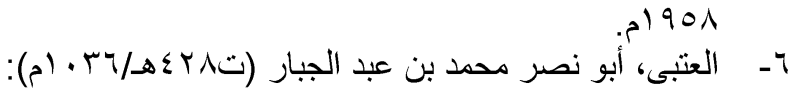




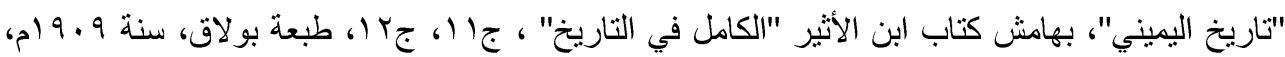

"صبح الأعىى في صناعة الإنشا"، تقديم فوزي محمد أمين، طبعة الهيئة العامة لقصور الثقافة سنة

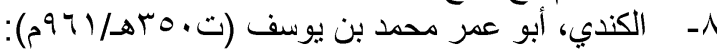

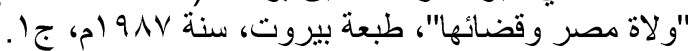

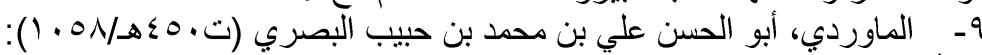

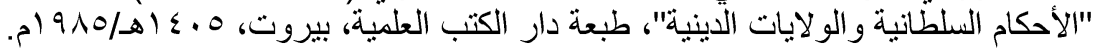

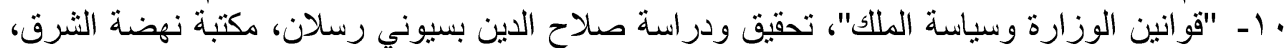

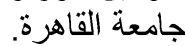

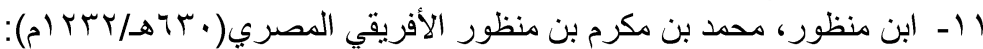

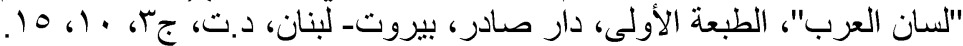

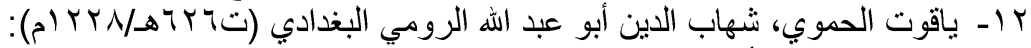

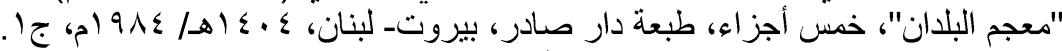

ثانيًا: المصادر والمراجع الفارسية:

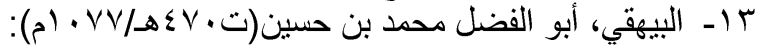

"تاريخ البيهقي"، ترجمة من الفارسية يحيى الخشاب، وصادق نشأت، مكتبة الأنجلو الصصرية،

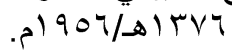

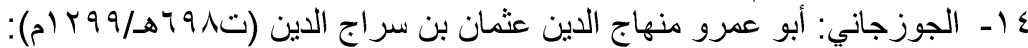

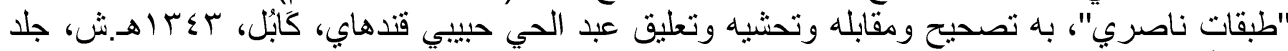

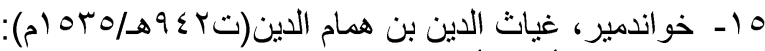

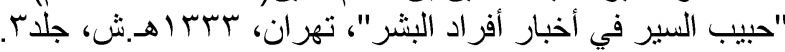

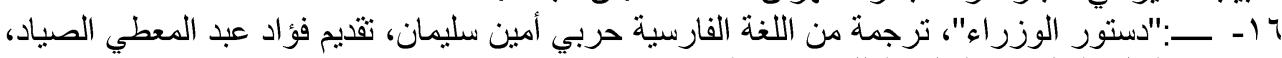

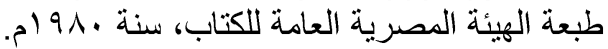

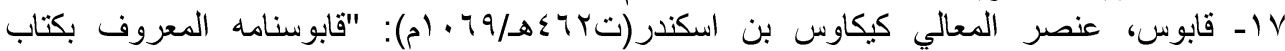

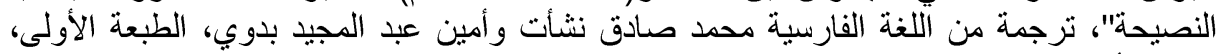

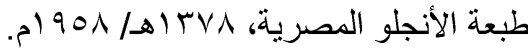

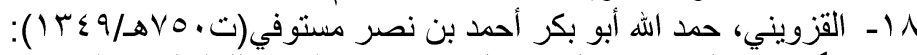

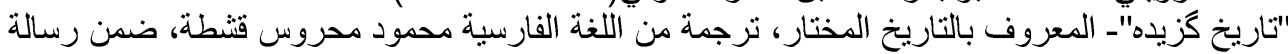

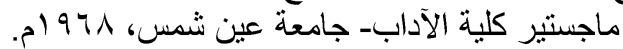

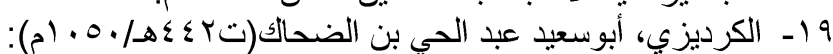

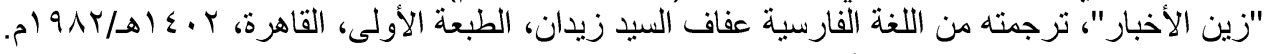

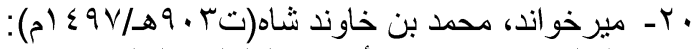

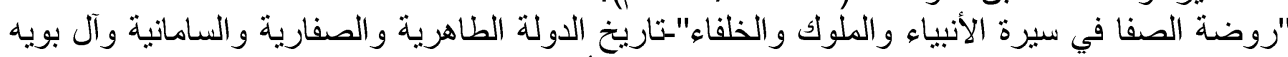

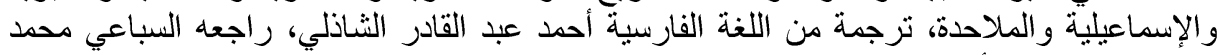

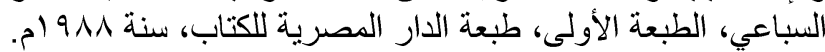

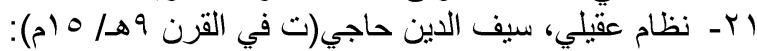

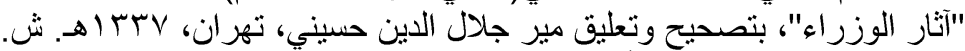

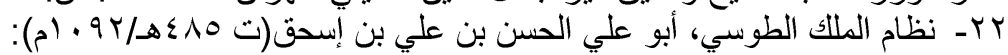

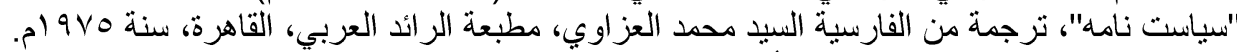

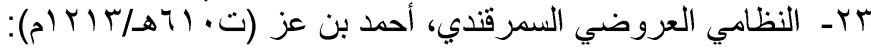




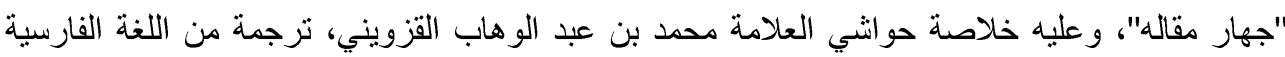

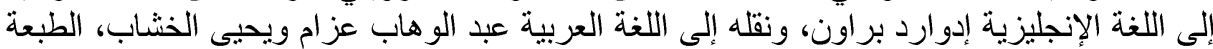

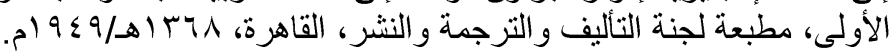

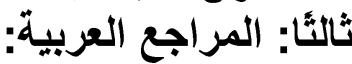

ع ז- الجوهري: "الصحاح تاج اللغة وصحاح العربية"، تحقيق أحمد عبد الغفور عطار، الطبعة الأولى، دار

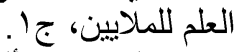

or- حسن البانثا: "الألقاب الإسلامية في التاريخ والوثائق والآثار"، الدار الفنية للنشر والتوزيع،

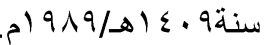
بr- مرتضي الزبيدي: "تاج العروس من جواهر القاموس"، تحقيق عبد الستار أحمد فراج، طبعة الكويت،

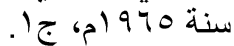

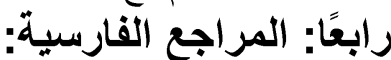

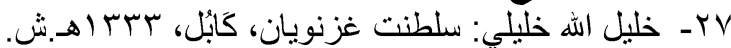

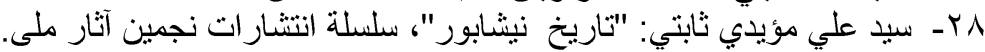
9r- عباس إقبال: تاريخ إيران بعد الإسلام من بداية الدولة الطاهرية حتى نهاية الداعية الدولة القاجارية، ترجمة

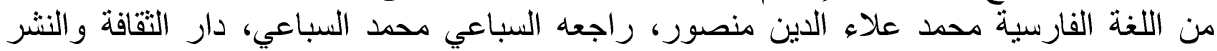

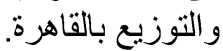

•r- منثي كرماني: "نسائم الأسحار في لطائف الأخبار در تاريخ وزراء"، بتصحيح ومقدمة مير جلال

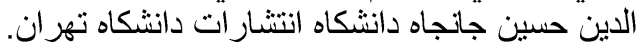

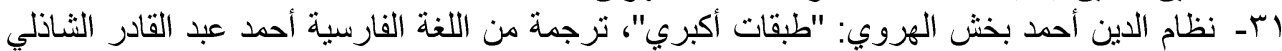

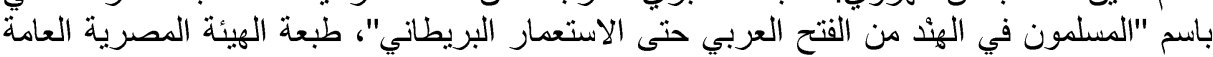

بr- بارنولد فاسيلي فلاديمير وفتش: المعان: "تركستان من الفتح العربي إلى الغزو المغولي"، ترجمه من اللغة

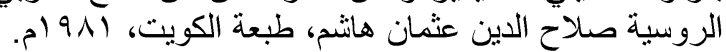

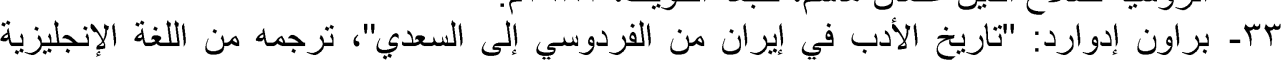

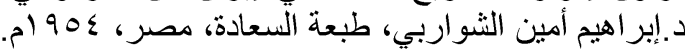

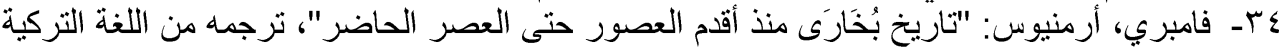

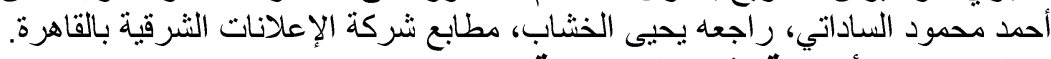

\section{رابعًا: المراجع الأجنبية غير المترجمة:}

ro- Bosworth C.E: "The Ghaznavids their empire in Afghanistan and Eastern Iran", (Edinburgh, 197\%).

rצ. -----: "The titulature of the early Ghaznavids Oriens", (Leiden, 197r).

rV_ Frye: Bukhara the medieval achievement, (London, 1970).

$r \wedge$ - Howorth: the Northern frontagers of china, journal of the royal asialic society, (London, 1919).

rq. Nazim M: the life and the time of sultan Mahmud of ghazn of arcward by the late sir, thomas Arnold, (Cambridge, 1941). 